\title{
Vertical cloud structure of warm conveyor belts - a comparison and evaluation of ERA5 reanalysis, CloudSat and CALIPSO data
}

\author{
Hanin Binder, Maxi Boettcher, Hanna Joos, Michael Sprenger, and Heini Wernli \\ Institute for Atmospheric and Climate Science, ETH Zurich, 8092 Zurich, Switzerland
}

Correspondence: Hanin Binder (hanin.binder@env.ethz.ch)

Received: 10 June 2020 - Discussion started: 24 June 2020

Revised: 30 August 2020 - Accepted: 25 September 2020 - Published: 19 October 2020

\begin{abstract}
Warm conveyor belts (WCBs) are important cyclone-related airstreams that are responsible for most of the cloud and precipitation formation in the extratropics. They can also substantially influence the dynamics of cyclones and the upper-level flow. So far, most of the knowledge about WCBs is based on model data from analyses, reanalyses and forecast data with only a few observational studies available. The aim of this work is to gain a detailed observational perspective on the vertical cloud and precipitation structure of WCBs during their inflow, ascent and outflow and to evaluate their representation in the new ERA5 reanalysis dataset. To this end, satellite observations from the CloudSat radar and the Cloud-Aerosol Lidar and Infrared Pathfinder Satellite Observation (CALIPSO) lidar are combined with an ERA5-based WCB climatology for nine Northern Hemisphere winters. Based on a case study and a composite analysis, the main findings can be summarized as follows. (i) WCB air masses are part of deep, strongly precipitating clouds, with cloud-top heights at 9-10 km during their ascent and an about 2-3 km deep layer with supercooled liquid water co-existing with ice above the melting layer. The maximum surface precipitation occurs when the WCB is at about 2-4 km height. (ii) Convective clouds can be observed above the inflow and during the ascent. (iii) At upper levels, the WCB outflow is typically located near the top of a $3 \mathrm{~km}$ deep cirrus layer. (iv) There is a large variability between WCBs in terms of cloud structure, peak reflectivity and associated surface precipitation. (v) The WCB trajectories with the highest radar reflectivities are mainly located over the North Atlantic and North Pacific, and - apart from the inflow - they occur at relatively low latitudes. They are associated with particularly deep and strongly precipitating clouds that occur not only during the ascent but also in the inflow
\end{abstract}

and outflow regions. (vi) ERA5 represents the WCB clouds remarkably well in terms of position, thermodynamic phase and frozen hydrometeor distribution, although it underestimates the high ice and snow values in the mixed-phase clouds near the melting layer. (vii) In the lower troposphere, high potential vorticity is diabatically produced along the WCB in areas with high reflectivities and hydrometeor contents, and at upper levels, low potential vorticity prevails in the cirrus layer in the WCB outflow. The study provides important observational insight into the internal cloud structure of WCBs and emphasizes the ability of ERA5 to essentially capture the observed pattern but also reveals many small- and mesoscale structures observed by the remote sensing instruments but not captured by ERA5.

\section{Introduction}

Extratropical cyclones are typically associated with welldefined, moist ascending airstreams referred to as warm conveyor belts (WCBs; e.g. Harrold, 1973; Carlson, 1980; Wernli and Davies, 1997). WCBs are responsible for most of the cloud and precipitation formation and poleward energy transport in extratropical cyclones (Browning, 1990), and they thereby play a crucial role for the hydrological cycle and the Earth's energy balance. WCBs are also essential from an atmospheric dynamical point of view. The intense cloud diabatic processes within the ascending airstreams lead to potential vorticity (PV) modifications in the lower and upper troposphere which can intensify the associated cyclone (Davis and Emanuel, 1991; Rossa et al., 2000; Binder et al., 2016) and influence the synoptic- and large-scale flow at 
the tropopause and the downstream weather evolution (e.g. Wernli and Davies, 1997; Grams et al., 2011).

Because of the crucial role of WCBs for many atmospheric processes, it is important to accurately represent them and the associated clouds and precipitation in numerical weather prediction and climate models. Several studies indicated that errors in their representation can lead to forecast errors in the weather downstream (e.g. Gray et al., 2014; MartínezAlvarado and Plant, 2014; Madonna et al., 2015; Grams et al., 2018). For instance, it has been shown that cloudmicrophysical processes in WCBs (Joos and Wernli, 2012; Joos and Forbes, 2016) and the initial moisture distribution in the WCB inflow (Schäfler et al., 2011; Schäfler and Harnisch, 2015) play a crucial role for the meso- and large-scale flow evolution. However, diabatic processes are difficult to represent in global models because they typically occur on smaller scales than the model resolution and must therefore be parameterized. Additionally, the understanding of many physical processes occurring in warm-, ice- and particularly mixed-phase clouds is still incomplete (e.g. Illingworth et al., 2007; Joos and Forbes, 2016). This highlights the importance of complementing our knowledge about WCBs and the embedded small-scale processes, which is mainly based on numerical model data, with observational studies.

Only a few observational studies exist on WCBs. Schäfler et al. (2011) compared lidar humidity observations of a summertime WCB over south-western Europe with analysis data from the European Centre for Medium-Range Weather Forecasts (ECMWF) and revealed significant deficiencies in the model's representation of the low-level moisture in the WCB inflow region. Crespo and Posselt (2016) analysed a WCB over the North Atlantic that was sampled several times by remote sensing instrumentation. They documented a clear transition from a stratiform to a convective cloud structure during the evolution of the cyclone. The distinction between mesoscale, slantwise ascent of the WCB and upright embedded convection had already been made in 1993 in a study on the mesoscale frontal structure of an explosively intensifying cyclone measured during the ERICA field experiment (Neiman et al., 1993). Embedded deep convection was also documented in a number of WCBs observed in the Mediterranean region (Flaounas et al., 2016; Flaounas et al., 2018) and during the North Atlantic Waveguide and Downstream Impact Experiment (NAWDEX) field campaign in the North Atlantic (Oertel et al., 2019; Blanchard et al., 2020). While slantwise WCB ascent leads to large-scale stratiform precipitation and the formation of widespread regions with lowPV air at upper levels, convective WCB ascent goes along with peaks of particularly strong surface precipitation and the formation of mesoscale upper-level PV dipoles, including regions with negative PV (Oertel et al., 2020). Finally, Gehring et al. (2020) investigated the snowfall microphysical processes in a strongly precipitating wintertime WCB over the Korean Peninsula that was observed with radar data, radio soundings and snowflake photographs. They showed how the WCB created ideal conditions for rapid precipitation growth, including the formation of supercooled liquid water in the strongly ascending air masses, which favoured intense riming and aggregation.

Many cloud processes, for example radiative heating or cooling of the atmosphere, condensational processes, and the efficiency of precipitation production, crucially depend on the vertical structure and distribution of clouds (e.g. Posselt et al., 2008). With the launch of the CloudSat radar (Stephens et al., 2002, 2008) and the Cloud-Aerosol Lidar and Infrared Pathfinder Satellite Observation (CALIPSO) lidar (Winker et al., 2003, 2009) in April 2006, high-resolution global measurements of the vertical structure and properties of clouds, precipitation and aerosols have become available. The satellites are part of NASA's Afternoon Train (A-Train), a constellation of satellites that travel in close formation in a sun-synchronous orbit, allowing for nearsimultaneous measurements of various key parameters that affect the Earth's weather and climate. Studies based on CloudSat and CALIPSO measurements have provided invaluable insight into the distribution of clouds and precipitation in extratropical cyclones and the associated complex dynamical and physical processes. Posselt et al. (2008) compared the frontal clouds observed by CloudSat along a warm, a cold and an occluded front with those described in the Norwegian polar-front model (Bjerknes and Solberg, 1922). While the historical description and the modern observations reveal remarkable similarities, CloudSat provides a detailed view of the internal cloud structure, thereby adding a new component to the classical conceptual model. Vertical composites of frontal clouds based on CloudSat and CALIPSO data (Naud et al., 2010, 2012, 2014, 2015) also revealed some similarities to the historical model but even more to the conveyor belt model and specifically the WCB, with mid- and high-level clouds typically occurring to the east of the cold front and above the warm front. Field et al. (2011) combined observations from CloudSat and passive sensors to create three-dimensional composites of the cloud and precipitation structure in extratropical cyclones and also used these to evaluate the representation of clouds and precipitation in a numerical model. CloudSat and CALIPSO observations have also been used to validate the global ice cloud representation in several versions of the ECMWF and UK Met Office models with different ice cloud parameterizations (Delanoë et al., 2011). It was found that the models generally reproduce the main geographical and temperature-dependent distributions, although with some deficiencies, and that the representation is considerably improved in schemes with prognostic variables for cloud ice, snow, liquid water and rain compared to schemes with diagnostic formulations for precipitation and mixed-phase clouds.

The objective of this study is to gain an observational view of a large number of WCBs in Northern Hemisphere winter, and to evaluate their representation in the new ERA5 reanalyses. For this, we combine satellite observations from 
CloudSat and CALIPSO with a WCB climatology compiled by ERA5. Specifically, the aims are to (i) use observational data to characterize the vertical cloud and precipitation structure of WCBs during their inflow, ascent and outflow in terms of vertical extent, radar reflectivity and ice water content, (ii) gain insight into the ERA5-based meteorological environment of the observed WCBs in terms of saturation, static stability and PV, (iii) quantify differences in the cloud structure and the meteorological environment between typical WCBs and WCBs with particularly high radar reflectivities, and (iv) assess the ability of ERA5 to represent ice and snow in WCB clouds in comparison to CloudSat and CALIPSO.

The remainder of the paper is organized as follows. Section 2 describes the satellite measurements and ERA5 reanalyses, as well as the method to combine the two datasets. In Sect. 3, we look at the cloud structure of an exemplary WCB in the North Pacific that was measured by the A-Train at the time of the strongest intensity of the associated cyclone. The climatological analysis of the vertical cloud structure of WCBs is presented in Sect. 4, and a summary and discussion of the results are provided in Sect. 5.

\section{Data and methods}

To characterize the vertical cloud and precipitation structure of the WCBs and to gain insight into the meteorological environment they are embedded in, satellite observations from the CloudSat radar and the CALIPSO lidar are combined with ERA5 reanalyses from the ECMWF. The period chosen for the study extends from December 2006 to the end of January 2016, and the analysis is confined to Northern Hemisphere winter (December-February). Winter 2011/2012 is excluded from the study as CloudSat was not part of the ATrain during that time period.

\subsection{Satellite observations}

Reflectivity profiles from the Cloud Profiling Radar (CPR) on board the polar-orbiting CloudSat satellite (Stephens et al., 2002, 2008; Tanelli et al., 2008) are used. The CPR is a nadir-pointing radar operating at a frequency of $94 \mathrm{GHz}$ ( $\sim 3 \mathrm{~mm}, \mathrm{~W}$-band). It provides cloud information with a vertical resolution of $485 \mathrm{~m}$ (oversampled to produce an effective resolution of $240 \mathrm{~m}$ ) between the surface and $30 \mathrm{~km}$ altitude. The horizontal resolution is about $1.7 \mathrm{~km}$ in an along-track direction (resulting from a pulse integration period of $0.16 \mathrm{~s}$ ) and $1.4 \mathrm{~km}$ in a cross-track direction. In the present study, we use CloudSat reflectivity data provided by the raDAR/liDAR (DARDAR) project (Delanoë and Hogan, 2010; see below), which is interpolated to a grid with $1.1 \mathrm{~km}$ horizontal and $60 \mathrm{~m}$ vertical resolution. The minimum detectable signal of the CPR is $-30 \mathrm{dBZ}$. Absorption mainly by liquid water results in a two-way attenuation of the radar signal which can amount to more than $10 \mathrm{dBZ} \mathrm{km}^{-1}$ below the melting layer and even lead to a full attenuation of the radar signal in strongly precipitating systems (Mace et al., 2007; Marchand et al., 2008). Reflectivity values between about -30 and $-15 \mathrm{dBZ}$ typically represent nonprecipitating clouds, values between -15 and $0 \mathrm{dBZ}$ drizzle or light rain, and values greater than $0 \mathrm{dBZ}$ rain with increasing intensity (Stephens and Haynes, 2007; Haynes et al., 2009). According to Haynes et al. (2009), unattenuated near-surface reflectivity values of more than $0 \mathrm{dBZ}(-5 \mathrm{dBZ})$ are almost certainly associated with significant surface rain (snow) rates of at least $0.03 \mathrm{~mm} \mathrm{~h}^{-1}$. Radar signals likely contaminated by surface or clear air clutter are filtered out in the present analysis with the CloudSat cloud mask from the 2B-GEOPROF product (Marchand et al., 2008). The effect of surface clutter is most pronounced below $1.2 \mathrm{~km}$ height (Marchand et al., 2008), which reduces the ability to investigate the cloud structure at the height of the WCB inflow.

Ice water content (IWC) profiles are obtained from the DARDAR cloud product version v1 (Delanoë and Hogan, 2010). They are derived using a variational method that combines CloudSat radar reflectivities, CALIPSO lidar attenuated backscatter and infrared radiometer data of the Moderate Resolution Imaging Spectroradiometer (MODIS) on board the Aqua satellite (for details see Delanoë and Hogan, 2008; Delanoë and Hogan, 2010). In addition, the ice cloud estimates depend on thermodynamic variables like temperature, pressure and specific humidity from the ECMWF-AUX dataset which contains ECMWF variables interpolated to the CloudSat radar bin. The CloudSat and CALIPSO products used to derive the IWC data are highly complementary and sensitive to very different powers of particle size. The radar is able to measure and penetrate optically thick clouds, but it cannot detect optically thin clouds with a reflectivity value below the minimum detectable signal of the radar $(-30 \mathrm{dBZ})$. On the other hand, the lidar is sensitive to optically thin clouds, but it is strongly attenuated in optically thick clouds. Therefore, by linking CloudSat, CALIPSO and other A-Train measurements, DARDAR combines the advantages of the different sensors, thereby providing a more detailed picture of the structure and microphysical properties of the hydrometeors than could be obtained by the individual sensors. The IWC retrievals consist of the entire frozen hydrometeor fraction without distinction between small ice crystals and sedimenting snow flakes. For each IWC value the associated uncertainty is estimated. Uncertainties can arise, for instance, from instrumental and measurement errors of the satellites, differences in the radar and lidar footprints, and errors associated with assumptions used in the variational scheme. They are expressed as 1 standard deviation percentage errors in the natural logarithm of the IWC and can reach up to about $60 \%$. Despite these significant uncertainties, the DARDAR cloud product currently comprises one of the most accurate estimates of ice cloud properties (Stein et al., 2011; Eliasson et al., 2013). Like the reflectiv- 
ity profiles, the IWC data are available on a grid with $1.1 \mathrm{~km}$ horizontal and $60 \mathrm{~m}$ vertical resolution.

\subsection{ERA5 reanalyses}

ERA5 reanalyses from the ECMWF (Hersbach et al., 2020) are used for the WCB identification and the characterization of the meteorological environment. ERA5 is based on the Integrated Forecast System model version cycle 41r2 that was operational in 2016. The reanalyses have a spectral resolution of T639 (corresponding to $\sim 31 \mathrm{~km}$ ) on 137 vertical levels and a temporal resolution of $1 \mathrm{~h}$. In this study, the fields are interpolated to a regular grid with $0.5^{\circ}$ horizontal resolution.

In ERA5, the parameterization of stratiform clouds and large-scale precipitation is based on an advanced version of the scheme developed by Tiedtke (1993) and includes prognostic variables for water vapour, cloud liquid water, cloud ice, rain, snow and grid box fractional cloud cover (ECMWF, 2016; see also Forbes and Ahlgrimm, 2014). Interactions between the various water species are described with parameterizations for condensation, deposition and freezing via stratiform and convective processes, evaporation, sublimation, and melting, as well as the generation of precipitation via autoconversion, accretion and snow riming. Precipitating particles have a terminal fall speed and can be advected between grid boxes by the three-dimensional wind. Supercooled liquid water can exist at temperatures between $0{ }^{\circ} \mathrm{C}$ and the homogeneous freezing threshold at $-38^{\circ} \mathrm{C}$. When ice and supercooled liquid co-exist, the ice crystals grow at the expense of the liquid water droplets via the WegenerBergeron-Findeisen mechanism. Convection is parameterized by a bulk mass flux scheme based on Tiedtke (1989) with a modified convective available potential energy closure (Bechtold et al., 2014). It considers deep, shallow and mid-level convection. The collective behaviour of a range of cumulus clouds in a grid cell is represented by a single pair of plumes describing the updraught and downdraught mass fluxes associated with the cloud ensemble, including the processes of entrainment of environmental air into the cloud and detrainment of cloud condensate into the environment.

\subsection{WCB identification}

The ERA5-based WCB trajectories are calculated with a slightly modified version of the algorithm developed by Madonna et al. (2014). Based on the Lagrangian analysis tool (LAGRANTO; Wernli and Davies, 1997; Sprenger and Wernli, 2015), trajectories are started every $6 \mathrm{~h}$ from an equidistant grid in the lower troposphere and calculated forward for $48 \mathrm{~h}$. For the climatological analysis, the starting points are located every $80 \mathrm{~km}$ in the horizontal direction and vertically every $20 \mathrm{hPa}$ between 1050 and $790 \mathrm{hPa}$, which is consistent with Madonna et al. (2014). For the case study, the horizontal resolution of the starting grid is increased to $40 \mathrm{~km}$. To be classified as WCB air parcels, the trajectories must experience a strong ascent of at least $600 \mathrm{hPa}$ within $48 \mathrm{~h}$ in the vicinity of an extratropical cyclone, whereby extratropical cyclones are identified as two-dimensional objects based on the algorithm of Wernli and Schwierz (2006) and refined in Sprenger et al. (2017). To exclude rapid ascent associated with tropical cyclones, the WCB trajectories are required to be north of $25^{\circ} \mathrm{N}$ during their ascent phase (at time $24 \mathrm{~h}$ ). With respect to the WCB identification method by Madonna et al. (2014), two modifications are made. (i) Very fast ascending trajectories that fulfil the $600 \mathrm{hPa}$ ascent criterion in the first part of the $48 \mathrm{~h}$ period and thereafter descend again are also selected. For those trajectories, the pressure difference between times 0 and $48 \mathrm{~h}$ can be lower than $600 \mathrm{hPa}$, and therefore they would have been neglected as WCB trajectories by the approach of Madonna et al. (2014). Compared to the original method, this leads to an increase in the number of identified WCB trajectories by about $35 \%$ (Katharina Heitmann, personal communication, 2020). (ii) WCB trajectories with a short distance to each other are clustered and considered to belong to the same WCB with a clustering method similar to the one described in Catto et al. (2015). When one of the trajectories in the cluster is collocated with a surface cyclone for at least one time step during the ascent, all the trajectories in the cluster are considered as WCB trajectories. Compared to the original algorithm, in which every single trajectory is required to be collocated with a surface cyclone, this leads to a further increase in the number of WCB trajectories by about $10 \%$. Despite the significant increase in the number of identified WCB trajectories with respect to the original WCB identification criterion, tests have shown that the modifications do not affect the findings of this study.

In the present study, the WCB trajectories are classified according to their height into inflow (0-2 km height corresponding to about $1000-800 \mathrm{hPa})$, ascent ( $2-7 \mathrm{~km}$ height and pressure $\sim 800-400 \mathrm{hPa}$ ) and outflow ( $>7 \mathrm{~km}$ height and pressure $<400 \mathrm{hPa}$ ).

\subsection{Matches between WCB trajectories and CloudSat and CALIPSO overpasses}

To combine the ERA5-based WCB trajectories with the satellite data, all WCB trajectories are selected that are overpassed by the CloudSat and CALIPSO satellites. Since the individual satellite profiles along the tracks are available about every $0.16 \mathrm{~s}$ and therefore much more often than the hourly ERA5 data, the ERA5 fields are assumed to be representative of a $1 \mathrm{~h}$ time range of $\pm 30 \mathrm{~min}$ around each full hour. A match between a WCB trajectory position and the satellites' tracks occurs when the trajectory is located within $50 \mathrm{~km}$ horizontal distance of the satellite orbit during this $1 \mathrm{~h}$ window (see Fig. 2b). In total, 509042 matches are identified between individual WCB trajectories and A-Train overpasses in the nine winters. These matches are associated with about 9000 different WCB clusters. 


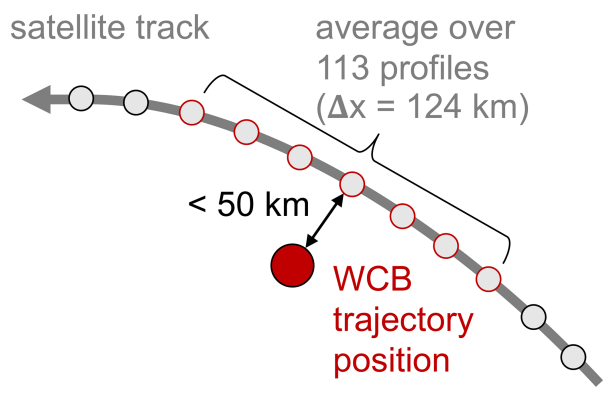

Figure 1. Schematic illustration of the method to attribute several satellite profiles to a matching ERA5-based WCB trajectory in the climatological analysis.

In the climatological study, several satellite profiles are attributed to each matching WCB trajectory. They are then averaged to increase the representativity of the observations (see schematic illustration in Fig. 1). In total, 113 satellite profiles are averaged per WCB match - that is, the profile with the closest distance to the WCB air parcel plus the 56 preceding and the 56 succeeding profiles. With a distance of $1.1 \mathrm{~km}$ between each satellite profile, the 113 assigned profiles correspond to a track segment length of about $124 \mathrm{~km}$ and therefore approximately the effective horizontal resolution of ERA5 (4 times the horizontal grid spacing), i.e. the smallest scale the model is able to resolve fully (see Abdalla et al., 2013). This allows for a better comparison between the observations and the model data. Consistent with earlier work (Illingworth et al., 2007; Delanoë et al., 2011), it is assumed that the narrow satellite track is representative of the three-dimensional model grid box.

\subsection{Selection of strong WCBs}

In addition to the analysis of the entire climatology of matching WCB trajectories, those with the highest reflectivity values given by CloudSat are investigated separately. More specifically, from all 509042 matches, in each $0.5 \mathrm{~km}$ height bin the $5 \%$ with the highest reflectivities at their respective height are selected and referred to as "strong WCBs". These top $5 \%$ in terms of reflectivity are assumed to be the strongest cloud-and-precipitation-producing WCB air parcels. A comparison of the entire climatology and the subcategory of strong WCBs allows to assess differences between the two categories in the cloud and precipitation structure, the geographical distribution, and the meteorological environment.

\section{Case study of a representative North Pacific WCB}

In this section, we examine the cloud and precipitation structure of a representative WCB that occurred in January 2014 over the central North Pacific. The associated cyclone underwent an explosive deepening and was observed by the A-
Train at the time of its strongest intensity (minimum sea level pressure of $975 \mathrm{hPa}$ ) around 00:00 UTC on 3 January 2014. At this time, the infrared satellite image and the overlaid ERA5 fields in Fig. 2a reveal a comma cloud pattern with high clouds along the cold, the warm and the intense bentback front and a distinct dry slot that wraps around the storm centre below a cyclonically breaking upper-level wave, shown by the 2 pvu contour at $315 \mathrm{~K}$. The yellow contour outlines the grid points where, according to the reanalysis data, at least one WCB air parcel is present somewhere in the vertical column. The large area encompassed by this contour indicates that the entire frontal region is influenced by WCB air. Note that these air parcels belong to WCB trajectories with a range of different starting times and vertical positions, with some still located at low levels at the beginning of their 2 day ascent, some in the middle of their ascent and some already located in the upper troposphere at the end of their 2 day ascent. As an example, Fig. $2 b$ shows WCB trajectories with starting times at 06:00 UTC on 2 January and their position $18 \mathrm{~h}$ later (black dots) at the time of the satellite overpass.

The A-Train moved from the south-east to the north-west over the warm sector, the cold and the warm fronts of the mature cyclone (blue line in Fig. 2a and b), and thereby simultaneously captured parts of the WCB inflow, ascent and outflow. In the warm sector south of $27^{\circ} \mathrm{N}$, the reflectivity profile measured by CloudSat (Fig. 3a and b) reveals shallow to mid-level convection above the WCB inflow, which is corroborated by the negative vertical gradient in equivalent potential temperature $\left(\theta_{\mathrm{e}}\right)$ between the surface and $4 \mathrm{~km}$ height. Between 27 and $33^{\circ} \mathrm{N}$, the WCB inflow is cloud-free and located below thin cirrus clouds in the WCB outflow that increase in thickness toward the cold front. At the cold front between 33 and $40^{\circ} \mathrm{N}$ and above large parts of the surface warm front between 42 and $46^{\circ} \mathrm{N}$, most of the deep cloud system is associated with WCB air (see purple dots in Fig. 3b that mark WCB air parcels). The high reflectivities (Fig. 3a) and satellite-retrieved IWC values (Fig. 3c) below 6-8 km indicate strong precipitation in the form of snow above and rain or melting snow below the $0^{\circ}$ isotherm. Unlike radars operating at centimetre wavelengths which exhibit a clear reflectivity peak at the melting layer, CloudSat's millimetre operating wavelength does not lead to a typical bright band at the melting layer but rather a dim band with reduced reflectivities (Sassen et al., 2007; Heymsfield et al., 2008). The dim band is due to snowfall attenuation and non-Rayleigh scattering effects, and it is evident both at the cold and at the warm front in the strongly precipitating cloud system (Fig. 3a). Above 6-8 km, at temperatures colder than about $-20^{\circ} \mathrm{C}$, the lower reflectivity and IWC values suggest ice clouds rather than falling snow. At the cold front, in the unstable air south of $37^{\circ} \mathrm{N}$, the presence of some narrow columns with particularly high reflectivities suggest convective WCB ascent embedded in the frontal cloud. In the northern part of the cold front, the higher static stability and horizontally relatively 

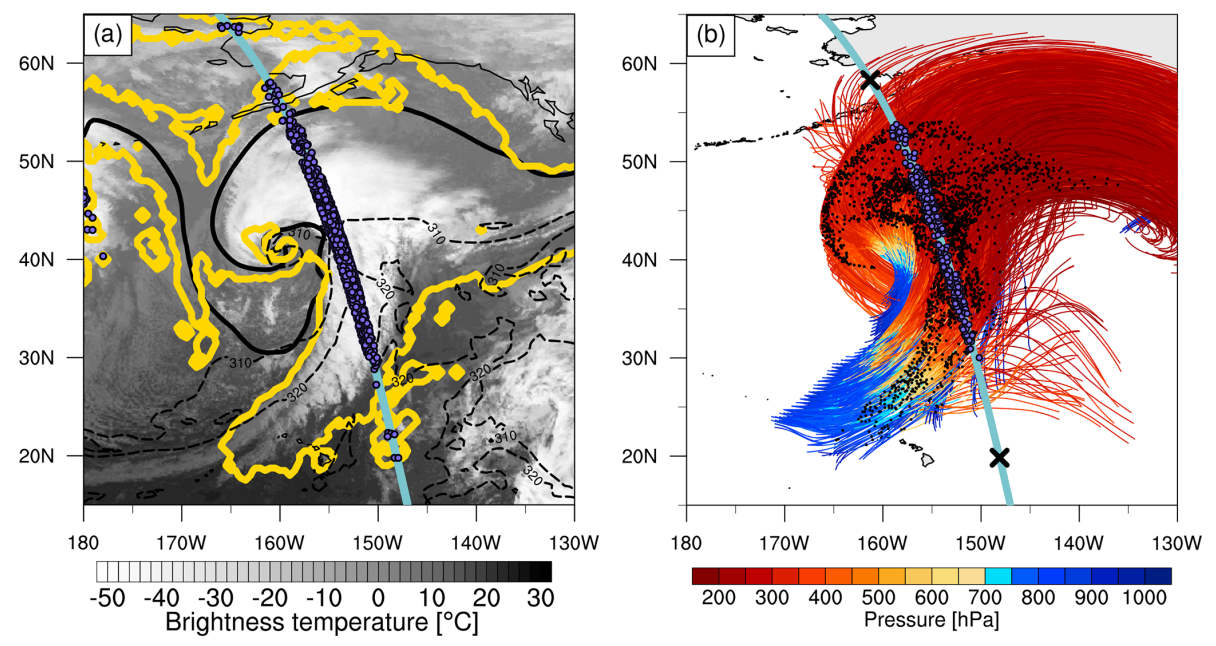

Figure 2. Case study of a North Pacific WCB at 00:00 UTC on 3 January 2014. (a) Infrared satellite image (brightness temperature in ${ }^{\circ} \mathrm{C}$ ) derived from the GridSat-B1 data (Knapp et al., 2011) and, from ERA5, the 2 pvu contour at $315 \mathrm{~K}$ (solid black), $\theta_{\mathrm{e}}$ (dashed black contours at 310 and $320 \mathrm{~K}$ ) and grid points with at least one WCB trajectory (yellow). The blue line marks the track of the A-Train, and the purple dots show matches between WCB air parcels and the satellite track. (b) The 2 day WCB trajectories (coloured by pressure; hPa) starting at 06:00 UTC on 2 January 2014. The positions of the trajectories at the time of the satellite overpass, 00:00 UTC on 3 January, are shown by black and purple dots, with the purple dots indicating matches with the satellite track (blue line). The segment of the satellite track between the two black crosses indicates the region shown in Fig. 3.

uniform reflectivities point to a mainly stratiform cloud structure. At the warm frontal zone, the WCB intersections with the satellite track indicate a gentle slantwise ascent along the tilted moist isentropes (Fig. 3b). North of $46^{\circ} \mathrm{N}$, the associated ice clouds decrease in thickness with increasing distance from the surface warm front as the cloud base slopes upward along the moist isentropes and the cloud-top height decreases.

Figure $3 \mathrm{~d}$ shows by colour the sum of the prognostic cloud ice and snow variables of ERA5 interpolated along the satellite track. To allow for a better comparison with the observations, in Fig. 3e the satellite-retrieved IWC is shown as the running mean over 113 satellite profiles, which corresponds to a track length of $124 \mathrm{~km}$ and thereby approximately the effective resolution of ERA5 (i.e. 4 times the horizontal grid spacing; see Abdalla et al., 2013). As noted in Sect. 2.1, the observations and ERA5 are not entirely independent as the satellite-retrieved IWC relies on thermodynamic variables from ECMWF analyses. In particular, the retrieved IWC is based on temperature profiles from the ECMWF to locate the melting layer height, which implies that by design the melting layer agrees well with ERA5. Despite this constraint, the satellite retrievals contain much additional information that is independent of the ECMWF data such that the comparison with ERA5 is meaningful and provides important insight into the quality of the model data.

A comparison of Fig. 3d and e shows that ERA5 captures the location of the cloud system and the broad ice and snow structure remarkably well. The sum over the ice and snow values strongly increases toward the melting layer and peaks right above the melting layer in the deep frontal clouds where most of it is present as falling snow (see thin black contours in Fig. 3d). However, the model considerably underestimates the peak values between the melting layer and the $-20^{\circ} \mathrm{C}$ isotherm (maxima of $1050 \mathrm{mg} \mathrm{m}^{-3}$ in ERA5 compared to $1630 \mathrm{mg} \mathrm{m}^{-3}$ in the observations) which are most likely associated with mixed-phase clouds. The underestimation is particularly pronounced in the convective clouds south of $27^{\circ} \mathrm{N}$. The 1 standard deviation percentage errors associated with the IWC retrievals in this case study are about $20 \%-$ $30 \%$ in the thin ice clouds at upper levels, $5 \%-20 \%$ around the $-20{ }^{\circ} \mathrm{C}$ isotherm and $10 \%-40 \%$ near the melting layer (not shown). The differences between the observations and ERA5 near the melting layer are therefore outside the error range of the observations even for values of $40 \%$. Furthermore, along the entire cross section, the cloud edges are less sharp in ERA5 than in the observations, and the transition between cloudy and cloud-free regions is smoother. Nevertheless, a comparison with ERA5's predecessor, ERA-Interim, reveals a strong improvement in the ice cloud representation in ERA5 (Binder, 2016). In ERA-Interim, the agreement with the observed IWC is very poor, in particular in the mixed-phase clouds where the underestimation of the high values close to the melting layer amounts to several orders of magnitude. The significant improvement of the representation from ERA-Interim to ERA5 can mainly be explained by a major upgrade of the cloud and precipitation parameterization (see also Delanoë et al., 2011; Forbes and Ahlgrimm, 2014): while ERA5 is based on prognostic variables for cloud ice, snow, liquid water and rain, in ERA-Interim precipitation 

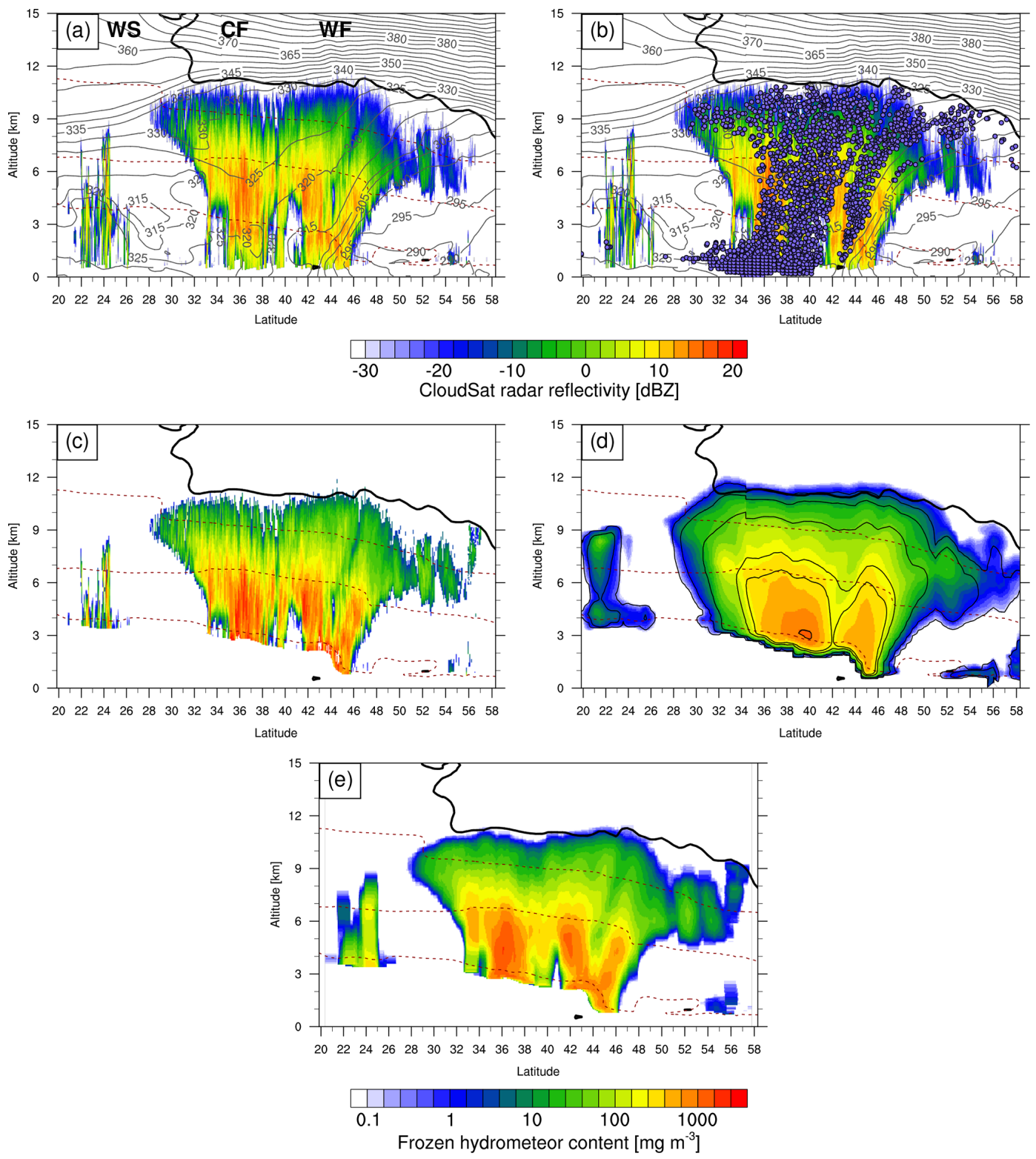

Figure 3. Vertical cross sections of observed and modelled variables along a North Pacific WCB at 00:00 UTC on 3 January 2014. (a) CloudSat radar reflectivity (dBZ; shading) along the segment between the two black crosses in Fig. 2b, together with, from ERA5, interpolated $\theta_{\mathrm{e}}$ (black contours every $5 \mathrm{~K}$ ), temperature (dashed red contours at $0,-20$ and $-40^{\circ} \mathrm{C}$ ) and the 2 pvu contour (thick black line). The labels mark the position of the warm sector ("WS"), the cold front ("CF") and the warm front ("WF"). (b) Same as (a) but with the positions of the intersected WCB trajectories shown by the purple dots. (c) DARDAR-retrieved IWC $\left(\mathrm{mg} \mathrm{m}^{-3}\right.$; shading), which consists of the entire frozen hydrometeor content, i.e. ice and falling snow, (d) ERA5-based frozen hydrometeor content, i.e. the sum of the prognostic cloud ice and snow water contents ( $\mathrm{mg} \mathrm{m}^{-3}$; shading), and prognostic snow water content only (thin black contours at $0.1,1,10,100,200$ and $1000 \mathrm{mg} \mathrm{m}^{-3}$ ), and (e) DARDAR-retrieved IWC in a running mean along 113 satellite profiles (corresponding to a segment of $\sim 124 \mathrm{~km}$ ). The thick black line in (c-e) again marks the 2 pvu contour, and the dashed red lines mark the $0,-20$ and $-40{ }^{\circ} \mathrm{C}$ isotherms.

and mixed-phase clouds are described by diagnostic formulations, and snow is not present in the frozen hydrometeor fraction but directly removed from the atmospheric column.

In summary, the case study of this North Pacific WCB reveals that (i) WCB air parcels form part of vertically extended, strongly precipitating clouds, but not the entire frontal cloud system is WCB air, (ii) convection can occur in the WCB inflow and ascent region, which is consistent with previous studies (e.g. Crespo and Posselt, 2016; Oertel et al., 2019), and (iii) the ERA5 reanalysis with prognostic variables for snow and ice is able to capture the broad structure and distribution of the frozen hydrometeor fraction associ- 
ated with the WCB cloud, but the peak values are underestimated.

\section{Climatological analysis of the WCB cloud structure}

In this section, the WCB clouds and their meteorological environment will be characterized climatologically for nine Northern Hemisphere winters. We will first discuss the spatial distribution of the matches between WCB trajectories and the A-Train and then investigate their vertical structure in satellite observations and reanalysis fields.

\subsection{Spatial distribution of the intersected WCB trajectories}

Figure 4a shows the spatial distribution of the 509042 matches between individual WCB trajectories and the ATrain overpasses. Matches occurred almost in the entire extratropics, but the highest number is present over the North Pacific and North Atlantic storm track regions between about 30 and $60^{\circ} \mathrm{N}$. This spatial pattern reflects the winter climatological distribution of WCBs during their inflow, ascent and outflow (blue contours). In general, in the southwestern ocean basins, most WCB air parcels were observed in the inflow, i.e. when the WCB trajectories were below $2 \mathrm{~km}$ height (pressure levels $>800 \mathrm{hPa}$ ), which is in agreement with the climatological maximum of WCB starting positions (Madonna et al., 2014). In contrast, in the northeastern part of the oceans at the end of the storm tracks, the majority of the matches occurred in the outflow, i.e. when WCB trajectories were above $7 \mathrm{~km}$ height (pressure levels $<400 \mathrm{hPa}$ ). Overall, the matches are distributed over a wide altitude range between the surface and $13 \mathrm{~km}$ height with the highest numbers below $2 \mathrm{~km}$ in the inflow and in particular between 7 and $10 \mathrm{~km}$ in the mid-latitude outflow (Fig. 4c). The latitude of the matches increases from the WCB inflow $\left(25\right.$ to $\left.50^{\circ} \mathrm{N}\right)$ to the outflow at a height of $8 \mathrm{~km}\left(35\right.$ to $\left.75^{\circ} \mathrm{N}\right)$ (mean and 10-90 inter-percentile range in green in Fig. 4d), reflecting the poleward motion typically occurring during the WCB ascent. Note, however, that the WCB air parcels in the different height bins generally belong to different WCB trajectories - only in rare cases the same trajectory has been observed more than once by the narrow CloudSat and CALIPSO tracks. Matches above $8 \mathrm{~km}$ typically occurred again at lower latitudes (where the tropopause is higher than in polar regions), ranging from about 30 to $60^{\circ} \mathrm{N}$ for air parcels at $10 \mathrm{~km}$ height and from 10 to $35^{\circ} \mathrm{N}$ for very high outflow above $12 \mathrm{~km}$. These matches are most likely associated with WCBs in convectively active subtropical systems.

The matches with strong WCBs, that is to say the $5 \%$ of the air parcels in each $0.5 \mathrm{~km}$ height bin with the highest CloudSat radar reflectivities (see Sect. 2.5), are mainly located over the North Pacific and North Atlantic (Fig. 4b).
Interestingly, in the inflow and early ascent $(<3.5 \mathrm{~km})$, the mean latitude of the WCB air parcels with exceptionally strong reflectivities is further north than the mean over all trajectories, with most air parcels located between 30 and $60^{\circ} \mathrm{N}$ (mean and 10-90 inter-percentile range in blue in Fig. 4d). The opposite is true at higher altitudes where the strong WCBs are typically located much further south than the entire climatology. Between 4 and $10 \mathrm{~km}$ height, their mean latitude is approximately constant around $38^{\circ} \mathrm{N}$, and matches at higher levels occur again at very low latitudes and are probably related to subtropical cyclones. Note, again, that different WCBs contribute to the strong category in each height bin, and the general decrease in the mean latitude from inflow to outflow observed for the strong WCBs does not imply an equatorward ascent. All in all, the analysis shows that WCBs with exceptionally strong radar reflectivities in their inflow occur further north than the mean of all matches, while higher than usual radar reflectivities in the WCB ascent and outflow are found further south.

\subsection{Composites of reflectivity and DARDAR-retrieved IWC}

To investigate the cloud structure of the WCBs during their inflow, ascent and outflow, we create vertical composites of the satellite observations separately for different WCB heights. Hereby, all matching WCB air parcels are classified into $0.5 \mathrm{~km}$ height bins with the number of matches per bin shown in the histogram in Fig. 4c. We will first examine the composites associated with the entire climatology and then compare them to the subcategory of strong WCBs.

\subsubsection{All WCBs}

Figure 5 shows composites of vertical profiles of CloudSat reflectivity (Fig. 5a) and DARDAR-retrieved IWC (Fig. 5b) as a function of the height at which the A-Train profile matched with a WCB trajectory. This height is referred to as $z \mathrm{WCB}$. For instance, for matches at a height of $z \mathrm{WCB}=$ $3 \mathrm{~km}$, the radar reflectivity shows median values exceeding $-6 \mathrm{dBZ}$ from near the ground to about $6 \mathrm{~km}$ altitude, whereas for matches above $z \mathrm{WCB}=7 \mathrm{~km}$, radar reflectivities are below $-30 \mathrm{dBZ}$ if the median is calculated over all WCBs (Fig. 5a). Thus, with increasing $z_{\text {WCB }}$, the composites give insight into the vertical cloud structure associated with the WCB inflow $(z \mathrm{WCB}=0-2 \mathrm{~km})$, ascent $(z \mathrm{WCB}=2-7 \mathrm{~km})$ and outflow $\left(z_{\mathrm{WCB}}>7 \mathrm{~km}\right)$. A comparison with the latitudeheight distribution of the matches (green line in Fig. 4d) shows that up to $z_{\mathrm{WCB}} \approx 8 \mathrm{~km}$ the satellite composites can be interpreted as a - somewhat irregular - vertical cross section from south to north through poleward ascending WCB air. However, keep in mind that the matching WCB air parcels in the different height bins correspond to different WCB trajectories such that Fig. 5 shows a composition of single WCB positions and not the development along individual trajecto- 

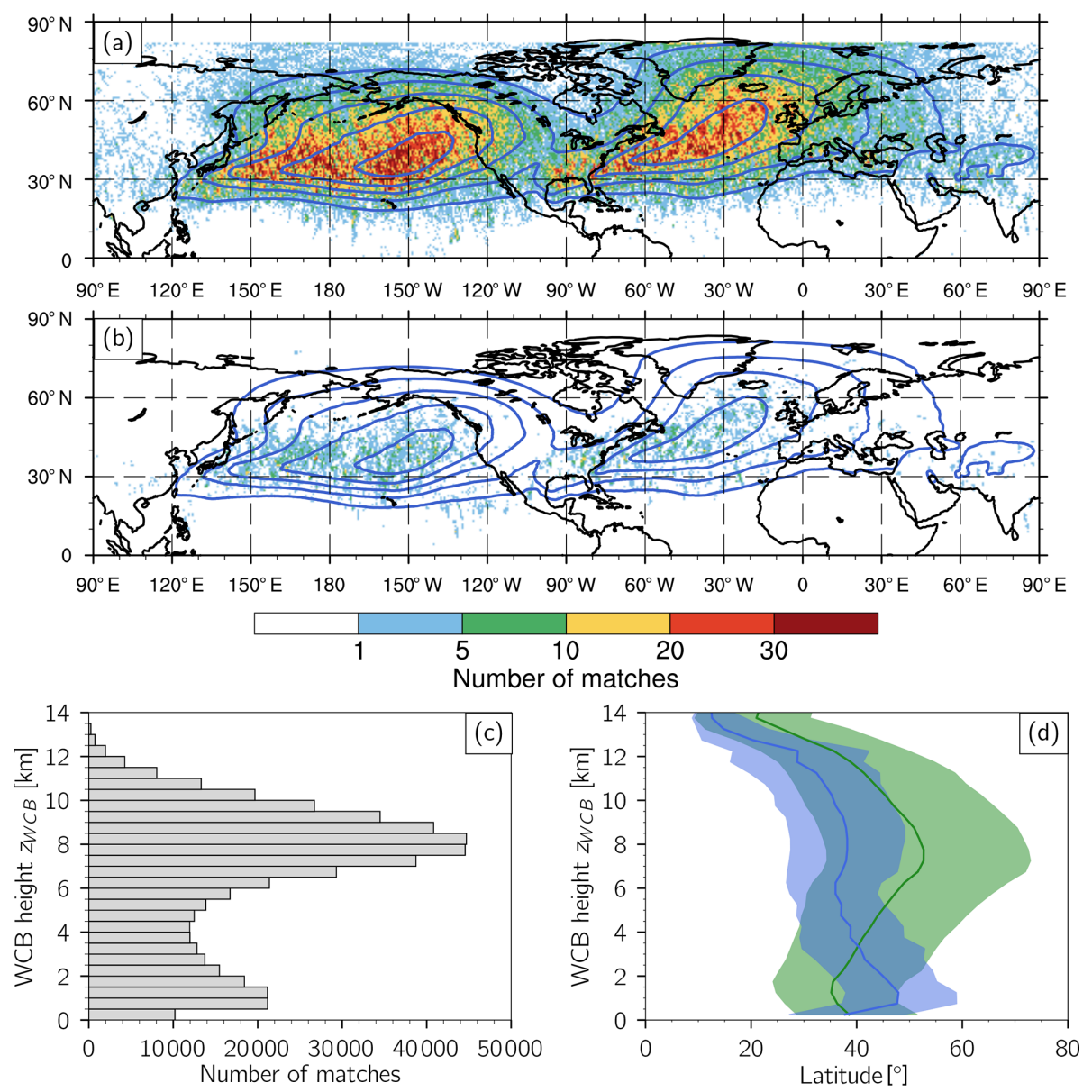

Figure 4. (a) Spatial distribution of the WCB trajectories matching with the satellite track (shading). The colours indicate the number of matches at each grid point. Overlaid is the ERA5-based climatological frequency of WCB trajectories for December-February 1980-2018 (blue contours every 10\%), whereby all time steps between the start $(t=0 \mathrm{~h})$ and the end $(t=48 \mathrm{~h})$ of the trajectories are considered. (b) As in (a) but for strong WCBs, i.e. the top $5 \%$ of the matches with highest reflectivity values in each vertical height bin. (c) Height distribution of the matches. (d) Latitude of the matches as a function of their height for all WCBs (green) and strong WCBs (blue). The green and blue lines show the mean over the matches, and the shadings represent the range between the 10th and the 90th percentiles.

ries. The calculation of median rather than mean profiles of the matches is motivated by the fact that, in the case of reflectivity, the median allows us to take into account clear-sky values, and, in the case of IWC, the mean would be dominated by large values. As seen in the case study, several matches can occur on top of each other in the same cloud system (see purple dots in Fig. 3b). In these cases, in the composites, the same satellite profile is taken into account for each match separately; i.e. it is present more than once along the $x$ axis. In summary, this sophisticated compositing approach is able to provide representative vertical profiles of observed radar reflectivity and IWC along WCBs in the Northern Hemisphere storm track regions in winter.

To quantify how often WCB matches occur on top of each other in the same cloud system, the black contours in Fig. 5a and $b$ show the relative WCB trajectory frequency, which is the number of matches in a certain $0.5 \mathrm{~km}$ profile height bin normalized by the total number of matches in the specific WCB height bin. For instance, a relative frequency of $10 \%$ at $z \mathrm{WCB}=3.75 \mathrm{~km}$ and $z_{\text {prof }}=9.75 \mathrm{~km}$ indicates that $10 \%$ of the WCB trajectories located between 3.5 and $4 \mathrm{~km}$ height have another WCB trajectory on top of them between 9.5 and $10 \mathrm{~km}$ height. Such a situation occurred, for instance, in the case study between about 36 and $45^{\circ} \mathrm{N}$ in the deep cold and warm frontal clouds (Fig. 3b). For matches at $z \mathrm{WCB}=1 \mathrm{~km}$ height, only in $5 \%$ of the cases was another WCB trajectory located on top of them at $9.5-10 \mathrm{~km}$ height. The vertical area in between can either also be associated with WCBs (as in the case study between 36 and $42^{\circ} \mathrm{N}$; Fig. $3 \mathrm{~b}$ ) or not (as between 30 and $36^{\circ} \mathrm{N}$ in Fig. $3 \mathrm{~b}$ ) - the frequency values do not provide insight into the vertical connectivity of the WCB air. By definition, the frequency is $100 \%$ along the diagonal line, and the slower its decrease away from the diagonal, the 

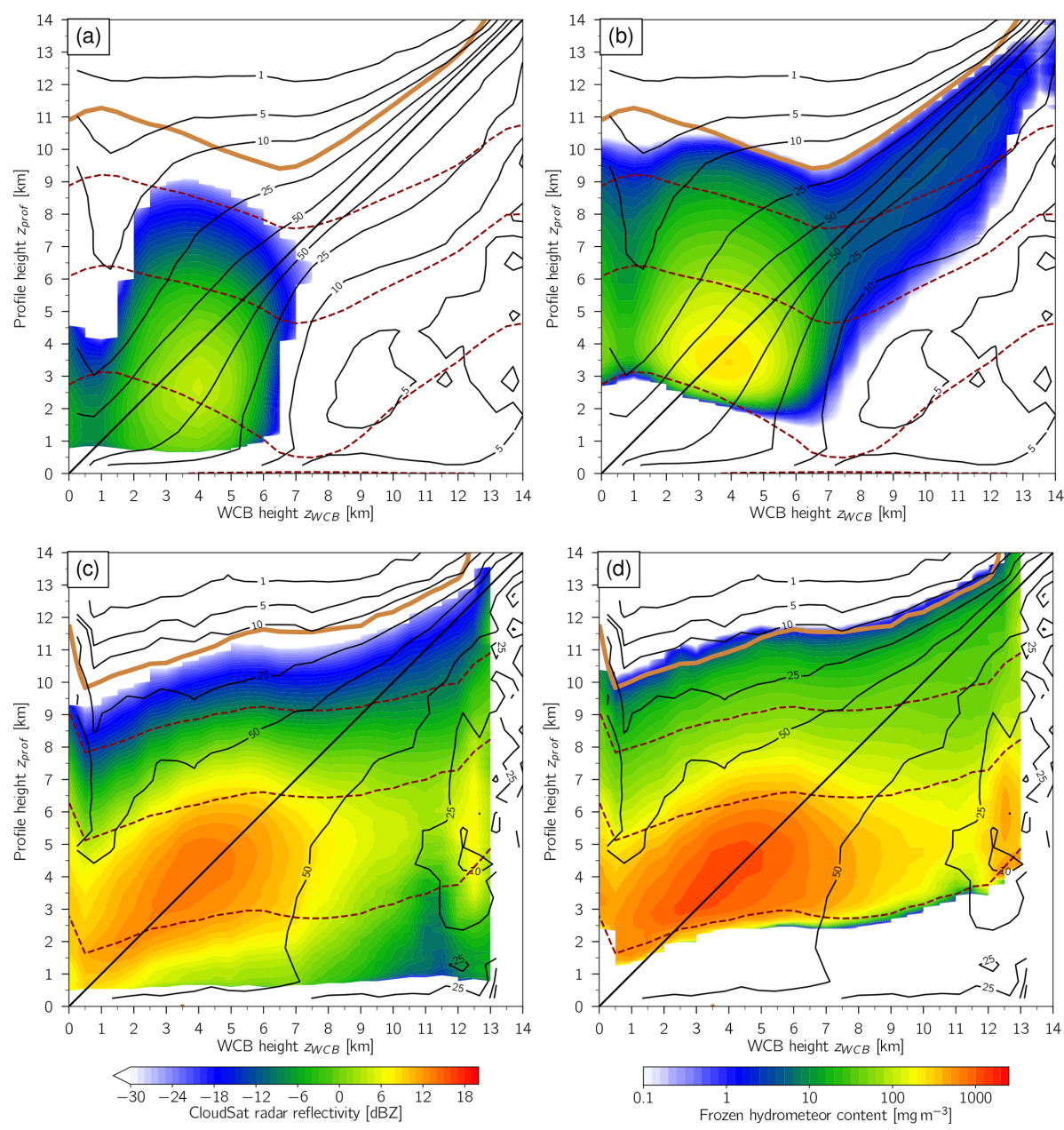

Figure 5. Composites for all WCBs $(\mathbf{a}, \mathbf{b})$ and strong WCBs $(\mathbf{c}, \mathbf{d})$ of the median vertical profiles of (a, c) CloudSat radar reflectivity (dBZ; shading) and (b, d) DARDAR-retrieved IWC ( $\mathrm{mg} \mathrm{m}^{-3}$; shading) separately for different height bins of the matching WCB air parcels (see text for details). The DARDAR-retrieved IWC in (b, d) consists of the entire frozen hydrometeor content, i.e. ice and falling snow. The black lines show the relative WCB trajectory frequency at each profile height (contours at $1 \%, 5 \%, 10 \%, 25 \%, 50 \%$ and $100 \%$ ), the dashed red line the temperature (contours at $0,-20$ and $-40{ }^{\circ} \mathrm{C}$ ) and the brown line the 2 pvu contour; all three fields are interpolated from ERA5.

more the observed reflectivity and IWC patterns are associated with WCB air.

In the reflectivity composite, the white areas indicate either clear air or, in particular below about $0.8 \mathrm{~km}$ height, ground clutter, which both have been filtered out (see Sect. 2.1). In the IWC composite, the white areas indicate the absence of frozen hydrometeors. The cloud-top heights according to the radar reflectivities are everywhere lower than those corresponding to the IWC retrievals. This can be explained by the inability of the radar to detect thin ice clouds with reflectivities below $-30 \mathrm{dBZ}$, whereas for the IWC retrievals the radar measurements are combined with lidar data that is strongly sensitive to optically thin ice clouds (see Sect. 2.1).

Overlaid on top of the observed fields are ERA5-based temperature contours (dashed red lines in Fig. 5a and b) and the dynamical tropopause (brown 2 pvu contour in Fig. 5a and $\mathrm{b}$ ). From $z_{\mathrm{WCB}}=0 \mathrm{~km}$ up to about $z_{\mathrm{WCB}}=8 \mathrm{~km}$, the melting layer and the dynamical tropopause decrease in height (Fig. 5a and b), which is consistent with the increase in mean latitude (green line in Fig. 4d), while between $z \mathrm{WCB}=8$ and $14 \mathrm{~km}$, the transition from predominantly subpolar to subtropical outflow is associated with an increase in their heights. At the height of the WCB inflow ( $z_{\mathrm{WCB}}$ and $z_{\mathrm{prof}} \approx 0-2 \mathrm{~km}$ ), liquid clouds with reflectivities of about -10 to $-5 \mathrm{dBZ}$ are present above the ground clutter (Fig. 5a), indicating some drizzle or light rain (Stephens and Haynes, 2007). Above the inflow, the small non-zero median IWC values reveal the presence of thin ice clouds that extend up to about $9-10 \mathrm{~km}$ height (Fig. 5b). As suggested by the low reflectivities below $-30 \mathrm{dBZ}$, this is most likely non-precipitating cirrus. The $5 \% \mathrm{WCB}$ trajectory contour approximately follows these ice clouds, indicating that a small fraction of them is associated with WCB air. 
During the ascent $\left(z_{\mathrm{WCB}} \approx 2-7 \mathrm{~km}\right)$, WCBs form part of deep clouds with cloud-top heights just below the ERA5based dynamical tropopause at $9-10 \mathrm{~km}$ (Fig. 5a and b). The clouds have relatively high reflectivity values up to more than $4 \mathrm{dBZ}$ and - between the melting layer and about $-20^{\circ} \mathrm{C}-$ a high DARDAR-retrieved IWC with peaks at $260 \mathrm{mg} \mathrm{m}^{-3}$, which indicates precipitation in the form of snow above and rain below the melting layer. The highest IWC values occur approximately at the height of the WCB, whereas the highest reflectivities are present just below the WCB slightly above the melting layer. The peak values, and therefore most likely the strongest surface precipitation, occur when the WCB trajectories are at a height of about $z \mathrm{WCB}=3.5-4 \mathrm{~km}$. Compared to the inflow, the WCB trajectory densities above and below the diagonal are higher in most of the ascent region, indicating a stronger contribution of WCB air to the reflectivity and IWC profiles. Of course, there is a large case-bycase variability, and the median profiles contain cloud systems that are almost entirely formed by strongly ascending WCB air and others for which only a small part of the deep cloud is WCB air. The decrease in the WCB densities to only about $10 \%$ at cloud base and cloud top suggests that the latter is often the case, i.e. the WCB ascent is typically embedded in a deeper cloud that forms partially due to air parcels with a weaker ascent than required for the WCB criterion.

In contrast to the ascent, the WCB outflow $\left(z_{\mathrm{WCB}}>7 \mathrm{~km}\right)$ is located within an about $3 \mathrm{~km}$ deep cirrus layer with low reflectivities below the sensitivity of the radar (Fig. 5a) and low IWC (1-10 $\mathrm{mg} \mathrm{m}^{-3}$; Fig. 5b). Their cloud bases and tops increase gradually with increasing outflow height, which suggests a predominantly slantwise ascent along the baroclinic zone similar to the pattern observed in the case study north of $46^{\circ} \mathrm{N}$ (Fig. 3). The deep cirrus layer and the extension of ice clouds above the WCB outflow level are in line with the findings of Wernli et al. (2016), who showed that the WCB outflow is often associated with cirrus clouds that form by the freezing of liquid droplets during the strong ascent, while above the outflow, in situ ice cloud formation can occur in response to the strong lifting associated with the WCB.

\subsubsection{Strong WCBs}

Analogous to the satellite composites created for all WCB matches, Fig. $5 \mathrm{c}$ and $\mathrm{d}$ show the median reflectivity and IWC profiles for the subcategory of strong WCBs, together with ERA5-based temperature contours and the dynamical tropopause. The slight decrease in latitude with increasing height of the WCB matches (blue line in Fig. 4d) is reflected in a general increase in the melting layer height and the tropopause along the $x$ axis (Fig. 5c and d) in contrast to the decrease observed for the entire climatology (Fig. 5a and b). It is again important to keep in mind that these composites cannot be interpreted in a Lagrangian way; the WCB air parcels in the different height bins generally belong to dif- ferent WCB trajectories, and the overall decrease in latitude with increasing $z$ WCB does not imply an equatorward ascent.

At the height of the WCB (along the diagonal) but also above and below, the reflectivities exceed those of all matches by $10-25 \mathrm{dBZ}$. Above the melting layer, this goes along with DARDAR-retrieved IWC values that are a factor of 5-5000 larger than those of all matches (Fig. 5d). This confirms that the top $5 \%$ of the matches in terms of radar signal are indeed very strongly cloud-and-precipitationproducing WCB trajectories. Deep clouds extending from the surface to the tropopause occur not only in the ascent region but - in contrast to all matches - also above the inflow and in the outflow. The cloud-top height according to the IWC pattern is at $10 \mathrm{~km}$ above the air parcels in the WCB inflow, at $11 \mathrm{~km}$ for the ascending ones and at $11-14 \mathrm{~km}$ for the outflow, and it is thus everywhere higher than for the entire climatology. The decrease in the WCB trajectory densities away from the diagonal is much slower than for all matches, implying a stronger contribution of WCB trajectories to the formation of the deep clouds. Presumably, WCB trajectories in the inflow, ascent and outflow are often located on top of each other in the same cloud system, as in the case study at the cold front (Fig. 3b). These results also indicate that a vertically deep layer of trajectories fulfilling the WCB criterion is likely leading to particularly high reflectivities and intense surface precipitation. The peak reflectivities $(13.9 \mathrm{dBZ}$ compared to $4.2 \mathrm{dBZ}$ for all matches) occur at the height of the ascending WCB and not below as for all matches, and the signal decrease below the WCB indicates strong snow and rain attenuation. The IWC maxima ( $1180 \mathrm{mg} \mathrm{m}^{-3}$ compared to $260 \mathrm{mg} \mathrm{m}^{-3}$ for all matches) are collocated with the reflectivity maxima. They extend over several WCB heights along the diagonal, from about $z \mathrm{WCB}=2.5 \mathrm{~km}$ to $z \mathrm{WCB}=$ $5 \mathrm{~km}$, in contrast to the rather localized peak at $z \mathrm{WCB}=3.5-$ $4 \mathrm{~km}$ observed for all matches. A secondary reflectivity and IWC maximum occurs at $z \mathrm{WCB}>12 \mathrm{~km}$ in the middle troposphere below the WCB outflow, and the low latitude of these matches (Fig. 4d) suggests that it is most likely associated with subtropical cyclones.

\subsection{Meteorological environment in ERA5}

To analyse the WCB clouds and the differences between all and strong WCBs in more detail, we complement the satellite observations with model data from ERA5. This allows us to gain insight into the meteorological environment associated with the matches and, at the same time, to compare the modelled ice and snow water content with the DARDAR observations. To this end, vertical profiles of the ERA5 fields are interpolated to the position of the matches, and composites equivalent to those discussed in the previous section are created. Again, we will first examine the fields for all WCB matches and then compare them with the subcategory of strong WCBs. 

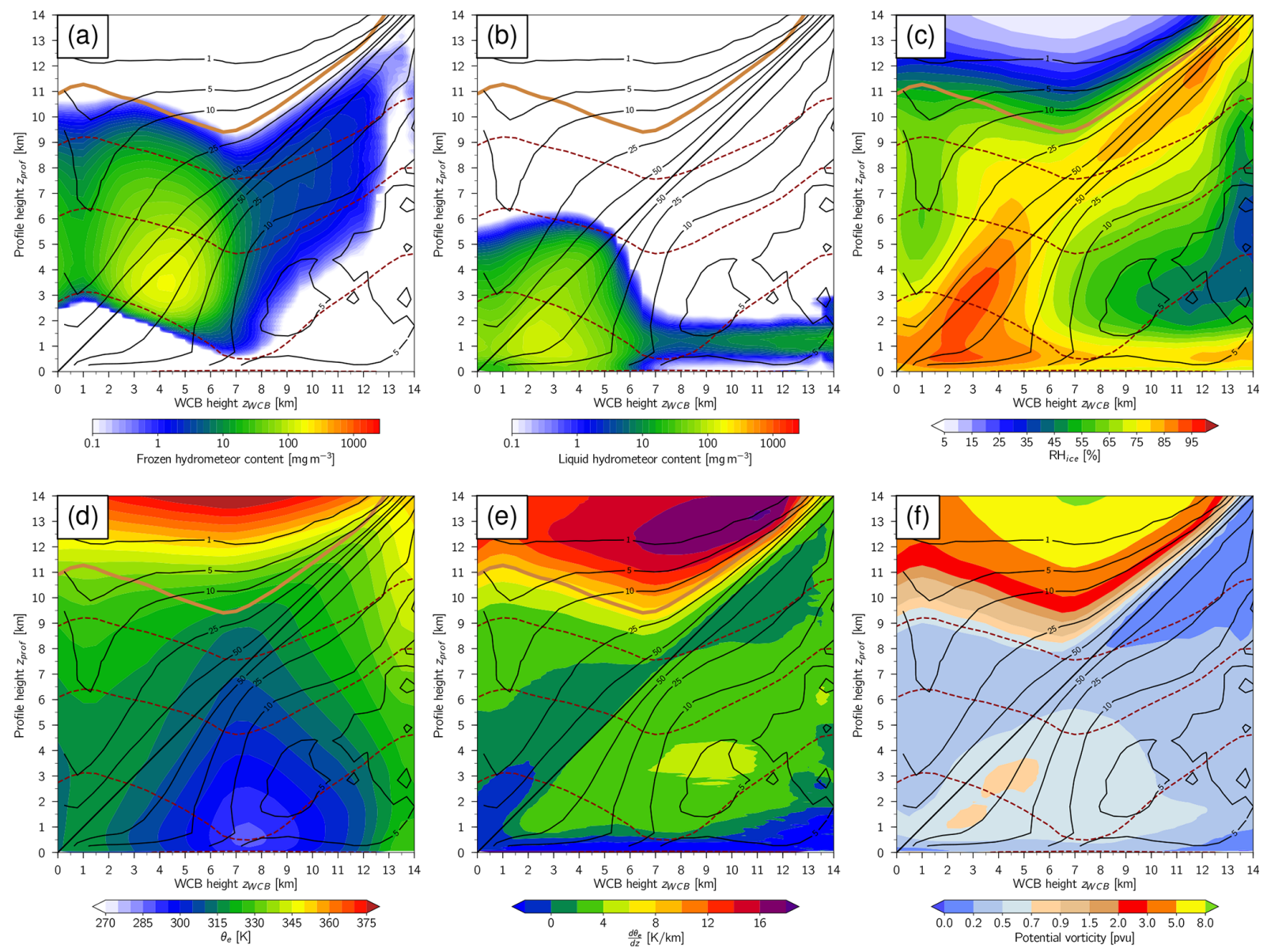

Figure 6. Composite over all WCBs of the (a, b) median and (c-f) mean vertical profiles of ERA5 fields separately for different height bins of the matching WCB air parcels. The shading shows (a) the frozen hydrometeor content $\left(\mathrm{mg} \mathrm{m}^{-3}\right)$, i.e. the sum of the prognostic cloud ice and snow water contents, (b) the liquid hydrometeor content $\left(\mathrm{mg} \mathrm{m}^{-3}\right)$, i.e. the sum of the prognostic cloud liquid water and rain water contents, (c) relative humidity with respect to ice $(\%),(\mathbf{d}) \theta_{\mathrm{e}}(\mathrm{K}),(\mathbf{e})$ moist vertical stability $\mathrm{d} \theta_{\mathrm{e}} / \mathrm{d} z\left(\mathrm{~K} \mathrm{~km}^{-1}\right)$, and (f) PV (pvu). The black and brown contours are as in Fig. 5.

\subsubsection{All WCBs}

The vertical composites of various ERA5 fields are shown in Fig. 6 separately for different WCB heights. Except for the frozen and liquid hydrometeor content, the mean rather than the median profiles are shown in each height bin as the fields are slightly smoother, but the median profiles are very similar. The frozen hydrometeor fraction, i.e. the sum of the prognostic cloud ice and snow variables (Fig. 6a), resembles the observed pattern in Fig. 5b remarkably well. However, in the ascent region between the melting layer and about $-20^{\circ} \mathrm{C}$, the peak values are underestimated $\left(160 \mathrm{mg} \mathrm{m}^{-3}\right.$ in ERA5 vs. $260 \mathrm{mg} \mathrm{m}^{-3}$ in the observations), whereas above the inflow and below the outflow the values are overestimated, and the cirrus layer associated with the outflow is considerably deeper than in the observations. Also, the transition between cloudy and cloud-free regions is smoother. Since the composites consist of a large number of satellite profiles, the mean errors associated with the IWC retrievals are much lower than the single values in the case study, with maximum errors of $0.17 \%$ coinciding with the maximum observed IWC values (not shown). The difference between the IWC values in ERA5 and the observations are therefore much larger than the observational uncertainty range both for the underestimated values in the ascent region and the overestimated values above the inflow and below the outflow. The underestimation of the peak values close to the melting layer is consistent with the case study. It occurs in a $2-3 \mathrm{~km}$ deep layer with mixed-phase clouds (Fig. 6b), which are known to be difficult to simulate and are associated with large uncertainties in many numerical weather prediction and climate models (e.g. Morrison et al., 2003; Illingworth et al., 2007; Klein et al., 2009; Delanoë et al., 2011).

The ice clouds in ERA5 coincide with high relative humidities with respect to ice $\left(\mathrm{RH}_{\text {ice }}\right.$; Fig. $\left.6 \mathrm{c}\right)$. The values are close to saturation $(>80 \%)$ along most of the WCB on the diagonal, and they are particularly high in a deep layer in the ascent region where the strong updraught continuously leads 


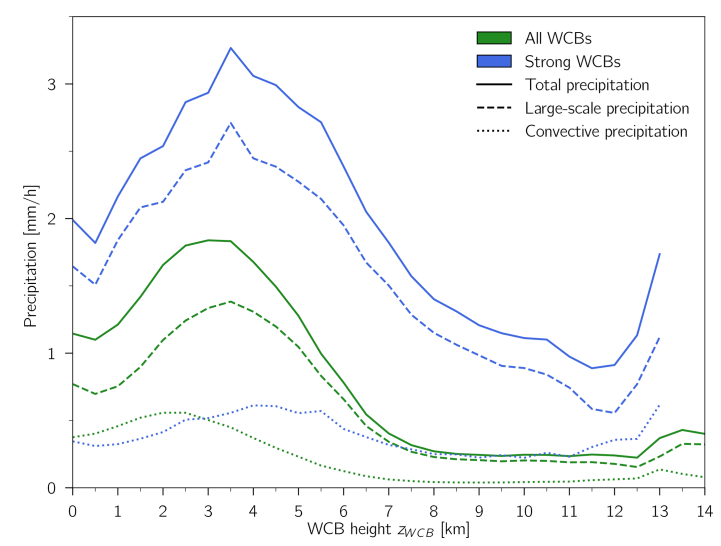

Figure 7. ERA5-based total (solid), large-scale (long-dashed) and convective (short-dashed) surface precipitation accumulated during the previous hour, averaged over all (green) and strong WCBs (blue), separately for different height bins of the matching WCB air parcels.

to new ice cloud formation. At lower altitudes, the inflow and especially the ascent regions are also associated with high cloud liquid water and rain water contents (Fig. 6b). The liquid hydrometeor fraction extends from the surface up to about $5-6 \mathrm{~km}$ height, with a $2-3 \mathrm{~km}$ deep layer of supercooled liquid water co-existing with ice above the melting layer. The highest liquid hydrometeor values occur during the WCB ascent $(z$ WCB at $\approx 2-4 \mathrm{~km})$ slightly below the WCB and the melting layer in the lower part of the vertically extended cloud. Accordingly, also the surface precipitation has a maximum when the WCB is at $2-4 \mathrm{~km}$ height, with values of about $1.8 \mathrm{~mm} \mathrm{~h}^{-1}$ (solid green line in Fig. 7). Surface precipitation is also high in the WCB inflow $\left(1.2-1.5 \mathrm{~mm} \mathrm{~h}^{-1}\right)$, whereas it is rather weak below the outflow $\left(0.3 \mathrm{~mm} \mathrm{~h}^{-1}\right)$. For $z \mathrm{WCB}>6-7 \mathrm{~km}$, the frozen and liquid hydrometeors are vertically disconnected (Fig. 6a and b), which is consistent with the tongue of relatively low $\mathrm{RH}_{\text {ice }}<70 \%$ in between (Fig. 6c). This suggests that the weak surface precipitation evident for $z_{\mathrm{WCB}}>6-7 \mathrm{~km}$ (Fig. 7) is not associated with the WCB but with the low-level warm clouds present at $1-2 \mathrm{~km}$ height below the WCB (Fig. 6b). Throughout the inflow, ascent and outflow, most of the surface precipitation is associated with the large-scale cloud scheme (Fig. 7). Convective precipitation is significantly lower but has a small peak in the inflow and early ascent. The presence of convection in the inflow is further corroborated by very low moist static stability values (i.e. weak vertical gradients in equivalent potential temperature, $\mathrm{d} \theta_{\mathrm{e}} / \mathrm{d} z$ ) in that region (Fig. 6d and e). Higher stabilities are present below the ascending WCB where the tilted moist isentropes indicate a lifting over the cold or warm front (Fig. 6d). At higher altitudes during the ascent, at and above the height of the WCB, the stabilities are again lower and indicate some convective motion.
The strong cloud and precipitation formation goes along with elevated PV values in the lower and middle troposphere and low PV in the WCB outflow (Fig. 6f). The elevated low- and mid-level PV ( $>0.5 \mathrm{pvu})$ extends over a broad and deep region in the inflow, ascent and early outflow $(z \mathrm{WCB}$ at $\approx 1-10 \mathrm{~km})$ and coincides with increased stability (Fig. 6e). Two areas with particularly high PV (>0.7 pvu) are located slightly below the ascending WCB $(z \mathrm{WCB}$ at $\approx 2-$ $5 \mathrm{~km}$; Fig. 6f). One of these two high low-level PV areas is located between the melting layer and the observed and modelled snow and ice maxima at WCB height (Figs. 5b and $6 \mathrm{a}$ ), and it coincides with the radar reflectivity maximum (Fig. 5a). Most likely, latent cooling of the melting layer and latent heating due to the freezing of cloud water and vapour deposition on ice particles along the WCB both contribute to the PV maximum in between. The agreement with the observations indicates that in addition to the good representation of cloud ice and snow in ERA5, the reanalysis data are able to capture the cloud diabatic processes associated with WCBs and their impact on the dynamics very well. The second area with high low-level PV (at $z$ WCB $\approx 2-3 \mathrm{~km}$ ) is located below the melting layer at $1-2 \mathrm{~km}$ profile height and coincides with the maximum in the modelled cloud rain and liquid water content (Fig. 6b), which suggests that here the PV production is mainly associated with latent heating due to condensation and potentially some below-cloud cooling due to rain evaporation. This PV maximum is not accompanied by a corresponding maximum in reflectivity (Fig. 5a), probably as a result of the two-way attenuation of the radar signal close to the surface in strongly precipitating systems. In the WCB outflow, the PV values are anomalously low ( $<0.2$ pvu; Fig. $6 f)$ and coincide with reduced vertical stability (Fig. 6e). As a consequence of the low-PV air in the outflow, the tropopause above is elevated, and a sharp vertical PV gradient is established between the low values at WCB height and the high values in the stratosphere. The elevated tropopause also goes along with an increased vertical gradient in equivalent potential temperature and a layer with peak vertical stability in the stratospheric air above the WCB outflow (Fig. 6d and e), which is referred to as the tropopause inversion layer (TIL; Birner et al., 2002). As discussed by Kunkel et al. (2016), the TIL typically forms above the WCB because (i) the lowlevel cloud diabatic processes lead to an increase in the vertical motion and an enhancement of static stability above the updraught region, and (ii) the upward transport of moisture into the tropopause region and the formation of high-level ice clouds goes along with strong radiative cooling at the tropopause which contributes to a further enhancement of the TIL.

\subsubsection{Strong WCBs}

The vertical composites of the ERA5 fields for the subcategory of strong WCBs are shown in Fig. 8. Again, the reanalysis correctly captures the broad structure and distribution 

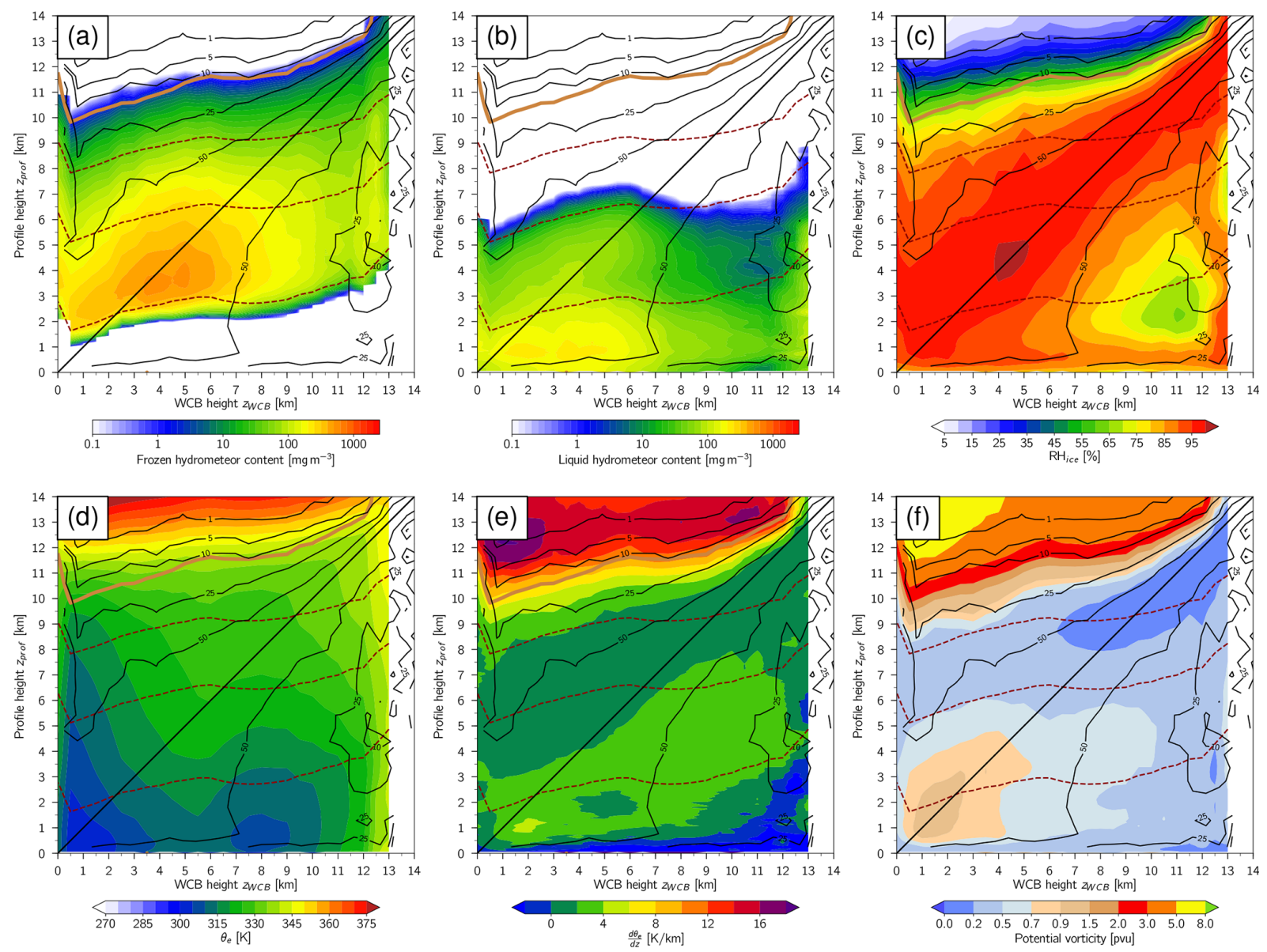

Figure 8. As Fig. 6 but for the category of strong WCBs.

of ice and snow along the WCBs (compare Figs. 8a and 5d) but underestimates the peak values in the mixed-phase layer ( $540 \mathrm{mg} \mathrm{m}^{-3}$ in ERA5 vs. $1180 \mathrm{mg} \mathrm{m}^{-3}$ in the observations). The observational uncertainty of the IWC values is slightly larger than for the entire climatology with maximum values of about $1 \%$ in the ascent region near the melting layer (not shown), but the difference between the observed and ERA5based IWC maxima is still significantly larger than the uncertainty range of the observations. Consistent with the satellite measurements (Fig. 5c and d), throughout the inflow, ascent and outflow, the modelled clouds associated with the strong WCBs are considerably deeper than those associated with the entire climatology, their hydrometeor contents are higher, the layer with mixed-phase clouds is deeper (Fig. 8a and b) and $\mathrm{RH}_{\text {ice }}$ is higher (Fig. 8c). This goes along with considerably higher surface precipitation along the entire WCB with peak values above $3 \mathrm{~mm} \mathrm{~h}^{-1}$ when the air parcels are at $3.5 \mathrm{~km}$ height and significant amounts also in the inflow and below the outflow (solid blue line in Fig. 7). In contrast to all WCB matches, there is no gap between the frozen and liquid hydrometeors throughout the inflow, ascent and outflow (Fig. 8a and b), which is consistent with the higher $\mathrm{RH}_{\text {ice }}$
(Fig. 8c). This suggests that also above $z$ WCB $\approx 6 \mathrm{~km}$ the surface precipitation is coming from the WCB and not from the low-level warm clouds as in the case of all matches. Along the entire WCB, most of the precipitation is again associated with the large-scale cloud scheme. The strongest convective precipitation occurs for WCBs around $4-5 \mathrm{~km}$ height and is potentially linked to a local minimum in moist static stability in the lower troposphere in that region (Fig. 8d and e). High values in the convective precipitation are also present at $z \mathrm{WCB}>12 \mathrm{~km}$, where high reflectivities and IWC values have been observed below the WCB outflow in Fig. 5c and $\mathrm{d}$. The presence of convection in this region is further supported by the high $\theta_{\mathrm{e}}$ values (Fig. 8d), the weak stratification (Fig. 8e) and the high $\mathrm{RH}_{\text {ice }}$ (Fig. 8c) throughout the depth of the troposphere. As mentioned in Sect. 4.2.2, this secondary cloud and precipitation maximum is most likely linked to subtropical cyclones.

The stronger cloud and precipitation formation in the subcategory of strong WCBs is reflected in stronger low-level PV production, in particular for WCBs in the inflow and early ascent, with peak values greater than 0.9 pvu (Fig. 8f). In contrast to the entire climatology, where the highest PV val- 
ues are located just below the WCB, for the strong category they occur along the WCB on the diagonal and coincide with the observed reflectivity and ice and snow maxima (Fig. 5c and d). Along the WCB, we expect the strongest latent heating due to condensation, freezing and vapour deposition on ice, which is consistent with the relative humidity maximum (Fig. 8c). Thus, the positive PV maximum coincides with the latent heating maximum, which is in line with the findings from previous studies (e.g. Wernli and Davies, 1997). In the WCB outflow, the PV values are anomalously low $(<0.2 \mathrm{pvu})$. As for the entire climatology, above the outflow the tropopause is elevated, and a tropopause inversion layer is evident (Fig. 8e and f).

\section{Summary and discussion}

In this study, ERA5 reanalyses have been combined with satellite observations from the polar-orbiting CloudSat radar and CALIPSO lidar to gain a detailed observational perspective on the vertical cloud structure of WCBs during their inflow, ascent and outflow and to evaluate their representation in ERA5. To this end, more than 500000 matches between the satellite observations and ERA5-based WCB trajectories (corresponding to about 9000 different WCB clusters) were evaluated during nine Northern Hemisphere winters in a composite analysis and a detailed case study. The majority of the matches occurred over the ocean basins in regions of high climatological WCB frequencies and can therefore be considered representative.

The satellite observations revealed that the WCBs form part of vertically extended, strongly precipitating clouds, in particular during their ascent, with cloud-top heights at 9$10 \mathrm{~km}$. In some cases, the entire cloud system is associated with WCB air, but often the cloud parts below and above the WCB air parcels form in air with a comparatively weak ascent below the WCB threshold. Convection can occur above the WCB inflow and during the ascent, which is in agreement with recent studies on convection embedded in WCBs (e.g. Crespo and Posselt, 2016; Flaounas et al., 2016; Oertel et al., 2019). In the upper troposphere after the main ascent phase, the WCBs are typically located near the top of an about $3 \mathrm{~km}$ deep layer with cirrus clouds.

According to ERA5, high low-level PV occurs below the ascending WCB in the lower part of the vertically extended cloud. The strongest low-level PV production occurs at about $3 \mathrm{~km}$ height between the melting layer and the ascending WCB and coincides with the radar reflectivity maximum. It is most likely produced by a combination of diabatic heating due to freezing of cloud water and depositional growth of ice particles at the WCB height and diabatic cooling from snow melting below. A second area with particularly strong lowlevel PV production occurs at about 1-2 km height, below the WCB and the melting layer in a region with strong cloudcondensational heating and possibly some below-cloud evap- orative cooling. The occurrence of the strongest positive PV anomalies below rather than at the WCB height is surprising, and the potentially important contribution of various in- and below-cloud microphysical processes to the low-level $\mathrm{PV}$ production is in line with the findings from recent modelling studies (Joos and Wernli, 2012; Crezee et al., 2017; Attinger et al., 2019).

The WCB trajectories with the highest reflectivity values (strong WCBs) have mainly been observed over the North Atlantic and North Pacific and - except in the inflow - at relatively low latitudes $\left(\sim 38^{\circ} \mathrm{N}\right)$. They are associated with particularly deep and strongly precipitating clouds that occur not only during the ascent but also in the inflow and outflow region. Compared to the climatology of all WCBs, the hydrometeor content is considerably higher and the surface precipitation is stronger. The low-level PV production is larger and has its peak in the inflow and early ascent at the height of the WCB, and it coincides with high reflectivities and hydrometeor values. The agreement of the positive PV anomaly with the region of strong cloud formation is characteristic for strongly ascending WCB air masses, where the PV anomaly, which is produced below the diabatic heating maximum, is advected upward toward the heating maximum (Wernli and Davies, 1997).

The comparison between the satellite retrievals and ERA5 showed that the reanalyses are able to capture the main structure of the WCB clouds in terms of position and thermodynamic cloud phase. The spatial pattern of the frozen hydrometeor fraction (ice and snow) is in good agreement with the observations, in particular at high altitudes where most of the frozen fraction is present as ice rather than falling snow. However, the peak values in the mixed-phase cloud regime near the melting layer are underestimated by a factor of 1.6 for the entire climatology and a factor of 2.4 for the subcategory of strong WCBs. This corroborates the findings from many other studies that mixed-phase clouds are difficult to simulate accurately (e.g. Illingworth et al., 2007; Delanoë et al., 2011). The co-existence of ice, supercooled liquid water and water vapour, as well as the complex interaction of various microphysical processes, render their understanding and parameterization in numerical weather prediction and climate models particularly challenging. Nevertheless, compared to the older reanalysis dataset ERAInterim (Dee et al., 2011), in which the microphysical parameterizations are based on simplified diagnostic relationships for snow and mixed-phase clouds, the improved scheme in ERA5 with prognostic variables for cloud ice, snow, liquid water and rain leads to a much more realistic representation of the WCB cloud pattern (Binder, 2016). This is consistent with the findings from Delanoë et al. (2011) and Forbes and Ahlgrimm (2014), who also compared CloudSat and CALIPSO observations with two ECMWF models with schemes similar to the ones in ERA5 and ERA-Interim, respectively, and found a significant improvement in the icecloud parameterization with the upgrade from the diagnostic 
to the prognostic representation of mixed-phase clouds and precipitation. As a caveat to the present study, it should be noted that the DARDAR-retrieved IWC depends on thermodynamic variables like temperature, pressure and specific humidity from ECMWF analyses and is therefore not entirely independent of the ERA5 data being evaluated. This illustrates the challenge in finding completely independent observations to validate cloud variables in model data. Nevertheless, the satellite retrievals contain much additional information not incorporated in ERA5, and they thereby allow for a meaningful comparison of the two datasets.

Following earlier studies (e.g. Illingworth et al., 2007; Delanoë et al., 2011), in the present analysis it has been assumed that the cloud structure observed along the narrow two-dimensional satellite track is representative of the entire three-dimensional volume of the model grid box. Despite a quite good agreement between ERA5 and the observations, it is possible that this assumption is not entirely justified and the clouds observed by the satellite are not representative of the larger-scale features. As proposed by Delanoë et al. (2011), additional information on the large-scale environment could be obtained from other instruments on board the A-Train satellites with a wider swath width in order to better assess the representativity of the measurements.

The CloudSat and CALIPSO measurements have provided a much needed, detailed observational perspective into the internal cloud structure of WCBs and have revealed many small- and mesoscale structures not resolved by the temporally and spatially much coarser-resolution model data that have mainly been used so far to study WCBs. The measurements complement the insight gained on WCBs from recent modelling studies with high-resolution convectionpermitting simulations (e.g. Oertel et al., 2020). In future work, the large number of WCB trajectories observed by CloudSat and CALIPSO could still be exploited in more detail, both in case studies and climatological analyses. They could be classified, for instance, according to different criteria like the position relative to the cyclone centre and the stage of the cyclone life cycle, the ascent behaviour (slantwise vs. convective), the outflow curvature (cyclonically vs. anticyclonically), the amplitude of the low-level positive and upper-level negative PV anomalies, or the geographical region in order to assess whether different types of WCBs have common characteristics. It would also be insightful to extend the climatological analysis to different seasons and the Southern Hemisphere to investigate potential seasonal and hemispheric differences in the WCB cloud structure. Finally, the study could be repeated with data from other models. In particular, it would be interesting to evaluate the representation of WCBs in operational numerical weather prediction models at different lead times, which might allow for the identification of systematic forecast errors.
Data availability. The DARDAR satellite products used in this study can be accessed from the ICARE website (https://www. icare.univ-lille.fr/dardar/, last access: 13 October 2020) (ICARE, 2020) and the ERA5 reanalyses from the ECMWF website (https:// www.ecmwf.int/en/forecasts/datasets/reanalysis-datasets/era5, last access: 13 October 2020) (European Centre for Medium Range Weather Forecasts, 2020). The matches between the WCB trajectories and the satellite data are available from the authors upon request.

Author contributions. MS calculated the ERA5 WCB climatology. $\mathrm{HB}$ performed all other analyses in this study and wrote the paper. $\mathrm{MB}, \mathrm{HJ}, \mathrm{MS}$ and $\mathrm{HW}$ contributed to the interpretation of the results and the writing of the paper.

Competing interests. The authors declare that they have no conflict of interest.

Acknowledgements. We thank the ICARE data and services centre for providing access to the DARDAR satellite data, and MeteoSwiss and ECMWF for access to the ERA5 reanalyses. We are grateful to Julien Delanoë, Paul Field, Josué Gehring, Catherine Naud and Derek Posselt for valuable comments and discussions.

Financial support. This research has been supported by the Swiss National Science Foundation (SNSF) (grant nos. 146834 and 185049) and the European Research Council 485 (ERC) (grant no. 787652).

Review statement. This paper was edited by Juliane Schwendike and reviewed by Derek J. Posselt and Josué Gehring.

\section{References}

Abdalla, S., Isaksen, L., Janssen, P., and Wedi, N.: Effective spectral resolution of ECMWF atmospheric forecast models, ECMWF Newslett., 137, 19-22, 2013.

Attinger, R., Spreitzer, E., Boettcher, M., Forbes, R., Wernli, H., and Joos, H.: Quantifying the role of individual diabatic processes for the formation of PV anomalies in a North Pacific cyclone, Q. J. Roy. Meteorol. Soc., 145, 2454-2476, 2019.

Bechtold, P., Semane, N., Lopez, P., Chaboureau, J.-P., Beljaars, A., and Bormann, N.: Representing equilibrium and nonequilibrium convection in large-scale models, J. Atmos. Sci., 71, 734-753, 2014.

Binder, H.: Warm conveyor belts: cloud structure and role for cyclone dynamics and extreme events, PhD thesis, No. 24016, ETH Zürich, Zürich, https://doi.org/10.3929/ethz-b-000164982, 2016.

Binder, H., Boettcher, M., Joos, H., and Wernli, H.: The role of warm conveyor belts for the intensification of extratropical cyclones in Northern Hemisphere winter, J. Atmos. Sci., 73, 39974020, 2016. 
Birner, T., Dörnbrack, A., and Schumann, U.: How sharp is the tropopause at midlatitudes?, Geophys. Res. Lett., 29, 1700, https://doi.org/10.1029/2002GL015142, 2002.

Bjerknes, J. and Solberg, H.: Life cycle of cyclones and the polar front theory of atmospheric circulation, Geophys. Publ., 3, 1-18, 1922.

Blanchard, N., Pantillon, F., Chaboureau, J.-P., and Delanoë, J.: Organization of convective ascents in a warm conveyor belt, Weather Clim. Dynam. Discuss., https://doi.org/10.5194/wcd2020-25, in review, 2020.

Browning, K. A.: Organization of clouds and precipitation in extratropical cyclones, in: Extratropical Cyclones: The Erik Palmén Memorial Volume, edited by: Newton, C. W. and Holopainen, E. O., Amer. Meteor. Soc., Boston, MA, USA, 129-153, 1990.

Carlson, T. N.: Airflow through midlatitude cyclones and the comma cloud pattern, Mon. Weather Rev., 108, 1498-1509, 1980.

Catto, J. L., Madonna, E., Joos, H., Rudeva, I., and Simmonds, I.: Global relationship between fronts and warm conveyor belts and the impact on extreme precipitation, J. Climate, 28, 8411-8429, 2015.

Crespo, J. A. and Posselt, D. J.: A-Train-based case study of stratiform-convective transition within a warm conveyor belt, Mon. Weather Rev., 144, 2069-2084, 2016.

Crezee, B., Joos, H., and Wernli, H.: The microphysical building blocks of low-level potential vorticity anomalies in an idealized extratropical cyclone, J. Atmos. Sci., 74, 1403-1416, 2017.

Davis, C. A. and Emanuel, K. A.: Potential vorticity diagnostics of cyclogenesis, Mon. Weather Rev., 119, 1929-1953, 1991.

Dee, D. P., Uppala, S. M., Simmons, A. J., Berrisford, P., Poli, P., Kobayashi, S., Andrae, U., Balmaseda, M. A., Balsamo, G., Bauer, P., Bechtold, P., Beljaars, A. C. M., van de Berg, L., Bidlot, J., Bormann, N., Delsol, C., Dragani, R., Fuentes, M., Geer, A. J., Haimberger, L., Healy, S. B., Hersbach, H., Hólm, E. V., Isaksen, L., Kållberg, P., Köhler, M., Matricardi, M., McNally, A. P., Monge-Sanz, B. M., Morcrette, J.-J., Park, B.-K., Peubey, C., de Rosnay, P., Tavolato, C., Thépaut, J.-N., and Vitart, F.: The ERA-Interim reanalysis: Configuration and performance of the data assimilation system, Q. J. Roy. Meteorol. Soc., 137, 553597, 2011.

Delanoë, J. and Hogan, R. J.: A variational scheme for retrieving ice cloud properties from combined radar, lidar, and infrared radiometer, J. Geophys. Res., 113, D07204, https://doi.org/10.1029/2007JD009000, 2008.

Delanoë, J. and Hogan, R. J.: Combined CloudSat-CALIPSOMODIS retrievals of the properties of ice clouds, J. Geophys. Res., 115, D00H29, https://doi.org/10.1029/2009JD012346, 2010

Delanoë, J., Hogan, R. J., Forbes, R. M., Bodas-Salcedo, A., and Stein, T. H. M.: Evaluation of ice cloud representation in the ECMWF and UK Met Office models using CloudSat and CALIPSO data, Q. J. Roy. Meteorol. Soc., 137, 2064-2078, 2011

ECMWF: IFS Documentation - Cy41r2. Part IV: Physical Processes, European Centre for Medium-Range Weather Forecasts, Reading, UK, 2016.

Eliasson, S., Holl, G., Buehler, S. A., Kuhn, T., Stengel, M., Iturbide-Sanchez, F., and Johnston, M.: Systematic and random errors between collocated satellite ice water path observations, J. Geophys. Res., 118, 2629-2642, 2013.

European Centre for Medium Range Weather Forecasts: ERA5, available at: https://www.ecmwf.int/en/forecasts/datasets/ reanalysis-datasets/era5, last access: 13 October 2020.

Field, P. R., Bodas-Salcedo, A., and Brooks, M. E.: Using model analysis and satellite data to assess cloud and precipitation in midlatitude cyclones, Q. J. Roy. Meteorol. Soc., 137, 1501-1515, 2011.

Flaounas, E., Lagouvardos, K., Kotroni, V., Claud, C., Delanoë, J., Flamant, C., Madonna, E., and Wernli, H.: Processes leading to heavy precipitation associated with two Mediterranean cyclones observed during the HyMeX SOP1, Q. J. Roy. Meteorol. Soc., 142, 275-286, 2016.

Flaounas, E., Kotroni, V., Lagouvardos, K., Gray, S. L., Rysman, J.-F., and Claud, C.: Heavy rainfall in Mediterranean cyclones. Part I: contribution of deep convection and warm conveyor belt, Clim. Dynam., 50, 2935-2949, 2018.

Forbes, R. M. and Ahlgrimm, M.: On the representation of highlatitude boundary layer mixed-phase cloud in the ECMWF global model, Mon. Weather Rev., 142, 3425-3445, 2014.

Gehring, J., Oertel, A., Vignon, É., Jullien, N., Besic, N., and Berne, A.: Microphysics and dynamics of snowfall associated with a warm conveyor belt over Korea, Atmos. Chem. Phys., 20, 7373 7392, https://doi.org/10.5194/acp-20-7373-2020, 2020.

Grams, C. M., Wernli, H., Böttcher, M., Čampa, J., Corsmeier, U., Jones, S. C., Keller, J. H., Lenz, C.-J., and Wiegand, L.: The key role of diabatic processes in modifying the upper-tropospheric wave guide: a North Atlantic case-study, Q. J. Roy. Meteorol. Soc., 137, 2174-2193, 2011.

Grams, C. M., Magnusson, L., and Madonna, E.: An atmospheric dynamics perspective on the amplification and propagation of forecast error in numerical weather prediction models: A case study, Q. J. Roy. Meteorol. Soc., 144, 2577-2591, 2018.

Gray, S. L., Dunning, C. M., Methven, J., Masato, G., and Chagnon, J. M.: Systematic model forecast error in Rossby wave structure, Geophys. Res. Lett., 41, 2979-2987, 2014.

Harrold, T. W.: Mechanisms influencing the distribution of precipitation within baroclinic disturbances, Q. J. Roy. Meteorol. Soc., 99, 232-251, 1973.

Haynes, J. M., L'Ecuyer, T. S., Stephens, G. L., Miller, S. D., Mitrescu, C., Wood, N. B., and Tanelli, S.: Rainfall retrieval over the ocean with spaceborne W-band radar, J. Geophys. Res., 114, D00A22, https://doi.org/10.1029/2008JD009973, 2009.

Hersbach, H., Bell, B., Berrisford, P., Hirahara, S., Horányi, A., Muñoz-Sabater, J., Nicolas, J., Peubey, C., Radu, R., Schepers, D., Simmons, A., Soci, C., Abdalla, S., Abellan, X., Balsamo, G., Bechtold, P., Biavati, G., Bidlot, J., Bonavita, M., De Chiara, G., Dahlgren, P., Dee, D., Diamantakis, M., Dragani, R., Flemming, J., Forbes, R., Fuentes, M., Geer, A., Haimberger, L., Healy, S., Hogan, R. J., Hólm, E., Janisková, M., Keeley, S., Laloyaux, P., Lopez, P., Lupu, C., Radnoti, G., de Rosnay, P., Rozum, I., Vamborg, F., Villaume, S., and Thépaut, J.-N.: The ERA5 global reanalysis, Q. J. Roy. Meteorol. Soc., 146, 1999-2049, 2020.

Heymsfield, A. J., Bansemer, A., Matrosov, S., and Tian, L.: The 94-GHz radar dim band: Relevance to ice cloud properties and CloudSat, Geophys. Res. Lett., 35, L03802, https://doi.org/10.1029/2007GL031361, 2008. 
ICARE: DARDAR, available at: https://www.icare.univ-lille.fr/ dardar/, last access: 13 October 2020.

Illingworth, A. J., Hogan, R. J., O’Connor, E. J., Bouniol, D., Brooks, M. E., Delanoë, J., Donovan, D. P., Eastment, J. D., Gaussiat, N., Goddard, W. F., Haeffelin, M., Klein Baltink, H., Krasnov, O. A., Pelon, J., Pirou, J.-M., Protat, A., Russchenberg, H. W. J., Seifert, A., Tompkins, A. M., Zadelhoff, G.-J., Vinit, F., Willén, U., Wilson, D. R., and Wrench, C. L.: Cloudnet - Continuous evaluation of cloud profiles in seven operational models using ground-based observations, B. Am. Meteorol. Soc., 88, 883-898, 2007.

Joos, H. and Forbes, R. M.: Impact of different IFS microphysics on a warm conveyor belt and the downstream flow evolution, Q. J. Roy. Meteorol. Soc., 142, 2727-2739, 2016.

Joos, H. and Wernli, H.: Influence of microphysical processes on the potential vorticity development in a warm conveyor belt: a casestudy with the limited-area model COSMO, Q. J. Roy. Meteorol. Soc., 138, 407-418, 2012.

Klein, S. A., McCoy, R. B., Morrison, H., Ackerman, A. S., Avramov, A., de Boer, G., Chen, M., Cole, J. N. S., Del Genio, A. D., Falk, M., Foster, M. J., Fridlind, A., Golaz, J.-C., Hashino, T., Harrington, J. Y., Hoose, C., Khairoutdinov, M. F., Larson, V. E., Liu, X., Luo, Y., McFarquhar, G. M., Menon, S., Neggers, R. A. J., Park, S., Poellot, M. R., Schmidt, J. M., Sednev, I., Shipway, B. J., Shupe, M. D., Spangenberg, D. A., Sud, Y. C., Turner, D. D., Veron, D. E., von Salzen, K., Walker, G. K., Wang, Z., Wolf, A. B., Xie, S., Xu, K.-M., Yang, F., and Zhang, G.: Intercomparison of model simulations of mixed-phase clouds observed during the ARM Mixed-Phase Arctic Cloud Experiment. I: Single-layer cloud, Q. J. Roy. Meteorol. Soc., 135, 979-1002, 2009.

Knapp, K. R., Ansari, S., Bain, C. L., Bourassa, M. A., Dickinson, M. J., Funk, C., Helms, C. N., Hennon, C. C., Holmes, C. D., Huffman, G. J., Kossin, J. P., Lee, H.-T., Loew, A., and Magnusdottir, G.: Globally gridded satellite observations for climate studies, B. Am. Meteorol. Soc., 92, 893-907, 2011.

Kunkel, D., Hoor, P., and Wirth, V.: The tropopause inversion layer in baroclinic life-cycle experiments: the role of diabatic processes, Atmos. Chem. Phys., 16, 541-560, https://doi.org/10.5194/acp-16-541-2016, 2016.

Mace, G. G., Marchand, R., Zhang, Q., and Stephens, G.: Global hydrometeor occurrence as observed by CloudSat: Initial observations from summer 2006, Geophys. Res. Lett., 34, L09808, https://doi.org/10.1029/2006GL029017, 2007.

Madonna, E., Wernli, H., Joos, H., and Martius, O.: Warm conveyor belts in the ERA-Interim dataset (1979-2010). Part I: Climatology and potential vorticity evolution, J. Climate, 27, 3-26, 2014.

Madonna, E., Boettcher, M., Grams, C. M., Joos, H., Martius, O., and Wernli, H.: Verification of North Atlantic warm conveyor belt outflows in ECMWF forecasts, Q. J. Roy. Meteorol. Soc., 141, 1333-1344, 2015.

Marchand, R., Mace, G. G., Ackerman, T., and Stephens, G.: Hydrometeor detection using CloudSat-An Earth-orbiting 94-GHz cloud radar, J. Atmos. Ocean. Tech., 25, 519-533, 2008.

Martínez-Alvarado, O. and Plant, R. S.: Parametrized diabatic processes in numerical simulations of an extratropical cyclone, Q. J. Roy. Meteorol. Soc., 140, 1742-1755, 2014.

Morrison, H., Shupe, M. D., and Curry, J. A.: Modeling clouds observed at SHEBA using a bulk microphysics parameterization implemented into a single-column model, J. Geophys. Res., 108, 4255, https://doi.org/10.1029/2002JD002229, 2003.

Naud, C. M., Del Genio, A. D., Bauer, M., and Kovari, W.: Cloud vertical distribution across warm and cold fronts in CloudSatCALIPSO data and a general circulation model, J. Climate, 23, 3397-3415, 2010.

Naud, C. M., Posselt, D. J., and Van Den Heever, S. C.: Observational analysis of cloud and precipitation in midlatitude cyclones: Northern versus Southern Hemisphere warm fronts, J. Climate, 25, 5135-5151, 2012.

Naud, C. M., Booth, J. F., and Del Genio, A. D.: Evaluation of ERA-Interim and MERRA cloudiness in the Southern Ocean, J. Climate, 27, 2109-2124, 2014.

Naud, C. M., Posselt, D. J., and van den Heever, S. C.: A CloudSatCALIPSO view of cloud and precipitation properties across cold fronts over the global oceans, J. Climate, 28, 6743-6762, 2015.

Neiman, P. J., Shapiro, M. A., and Fedor, L. S.: The life cycle of an extratropical marine cyclone. Part II: Mesoscale structure and diagnostics, Mon. Weather Rev., 121, 2177-2199, 1993.

Oertel, A., Boettcher, M., Joos, H., Sprenger, M., Konow, H., Hagen, M., and Wernli, H.: Convective activity in an extratropical cyclone and its warm conveyor belt - a case-study combining observations and a convection-permitting model simulation, Q. J. Roy. Meteorol. Soc., 145, 1406-1426, 2019.

Oertel, A., Boettcher, M., Joos, H., Sprenger, M., and Wernli, H.: Potential vorticity structure of embedded convection in a warm conveyor belt and its relevance for large-scale dynamics, Weather Clim. Dynam., 1, 127-153, https://doi.org/10.5194/wcd-1-1272020, 2020.

Posselt, D. J., Stephens, G. L., and Miller, M.: CLOUDSAT adding a new dimension to a classical view of extratropical cyclones, $\mathrm{B}$. Am. Meteorol. Soc., 89, 599-609, 2008.

Rossa, A. M., Wernli, H., and Davies, H. C.: Growth and decay of an extra-tropical cyclone's PV-tower, Meteorol. Atmos. Phys., 73, 139-156, 2000.

Sassen, K., Matrosov, S., and Campbell, J.: CloudSat spaceborne $94 \mathrm{GHz}$ radar bright bands in the melting layer: An attenuationdriven upside-down lidar analog, Geophys. Res. Lett., 34, L16818, https://doi.org/10.1029/2007GL030291, 2007.

Schäfler, A. and Harnisch, F.: Impact of the inflow moisture on the evolution of a warm conveyor belt, Q. J. Roy. Meteorol. Soc., 141, 299-310, 2015.

Schäfler, A., Dörnbrack, A., Wernli, H., Kiemle, C., and Pfahl, S.: Airborne lidar observations in the inflow region of a warm conveyor belt, Q. J. Roy. Meteorol. Soc., 137, 1257-1272, 2011.

Sprenger, M. and Wernli, H.: The LAGRANTO Lagrangian analysis tool - version 2.0, Geosci. Model Dev., 8, 2569-2586, https://doi.org/10.5194/gmd-8-2569-2015, 2015.

Sprenger, M., Fragkoulidis, G., Binder, H., Croci-Maspoli, M., Graf, P., Grams, C. M., Knippertz, P., Madonna, E., Schemm, S., Škerlak, B., and Wernli, H.: Global climatologies of Eulerian and Lagrangian flow features based on ERA-Interim, B. Am. Meteorol. Soc., 98, 1739-1748, 2017.

Stein, T. H. M., Delanoë, J., and Hogan, R. J.: A comparison among four different retrieval methods for ice-cloud properties using data from CloudSat, CALIPSO, and MODIS, J. Appl. Meteorol. Clim., 50, 1952-1969, 2011. 
Stephens, G. L. and Haynes, J. M.: Near global observations of the warm rain coalescence process, Geophys. Res. Lett., 34, L20805, https://doi.org/10.1029/2007GL030259, 2007.

Stephens, G. L., Vane, D. G., Boain, R. J., Mace, G. G., Sassen, K., Wang, Z., Illingworth, A. J., O'Connor, E. J., Rossow, W. B., Durden, S. L., Miller, S. D., Austin, R. T., Benedetti, A., Mitrescu, C., and the CloudSat Science Team: The CloudSat mission and the A-Train: A new dimension of space-based observations of clouds and precipitation, B. Am. Meteorol. Soc., 83, 1771-1790, 2002.

Stephens, G. L., Vane, D. G., Tanelli, S., Im, E., Durden, S., Rokey, M., Reinke, D., Partain, P., Mace, G. G., Austin, R., L'Ecuyer, T., Haynes, J., Lebsock, M., Suzuki, K., Waliser, D., Wu, D., Kay, J., Gettelman, A., Wang, Z., and Marchand, R.: CloudSat mission: Performance and early science after the first year of operation, J. Geophys. Res., 113, D00A18, https://doi.org/10.1029/2008JD009982, 2008.

Tanelli, S., Durden, S. L., Im, E., Pak, K. S., Reinke, D. G., Partain, P., Haynes, J. M., and Marchand, R. T.: CloudSat's cloud profiling radar after two years in orbit: Performance, calibration, and processing, IEEE T. Geosci. Remote, 46, 3560-3573, 2008.
Tiedtke, M.: A comprehensive mass flux scheme for cumulus parameterization in large-scale models, Mon. Weather Rev., 117, 1779-1800, 1989.

Tiedtke, M.: Representation of clouds in large-scale models, Mon. Weather Rev., 121, 3040-3061, 1993.

Wernli, H. and Davies, H. C.: A Lagrangian-based analysis of extratropical cyclones. I: The method and some applications, Q. J. Roy. Meteorol. Soc., 123, 467-489, 1997.

Wernli, H. and Schwierz, C.: Surface cyclones in the ERA-40 dataset (1958-2001). Part I: Novel identification method and global climatology, J. Atmos. Sci., 63, 2486-2507, 2006.

Wernli, H., Boettcher, M., Joos, H., Miltenberger, A. K., and Spichtinger, P.: A trajectory-based classification of ERA-Interim ice clouds in the region of the North Atlantic storm track, Geophys. Res. Lett., 43, 6657-6664, 2016.

Winker, D. M., Pelon, J. R., and McCormick, M. P.: The CALIPSO mission: spaceborne lidar for observation of aerosols and clouds, Proc. SPIE, 4893, 1-11, 2003.

Winker, D. M., Vaughan, M. A., Omar, A., Hu, Y., Powell, K. A., Liu, Z., Hunt, W. H., and Young, S. A.: Overview of the CALIPSO mission and CALIOP data processing algorithms, J. Atmos. Ocean. Tech., 26, 2310-2323, 2009. 